\title{
On the effects of anisotropic rheology on ice flow, internal structure, and the age-depth relationship at ice divides
}

\author{
Carlos Martín, ${ }^{1}$ G. Hilmar Gudmundsson, ${ }^{1}$ Hamish D. Pritchard, ${ }^{1}$ and Olivier Gagliardini ${ }^{2}$
}

Received 19 November 2008; revised 18 June 2009; accepted 10 July 2009; published 14 October 2009.

[1] We use numerical modeling with a full-system Stokes solver to elucidate the effects of nonlinear rheology and strain-induced anisotropy on ice flow at ice divides. We find that anisotropic rheology profoundly affects the shape of both isochrone layering and surface topography. Anisotropic effects cause the formation of a downward curving fold, i.e., a syncline, in isochrones in the lower central area beneath the ice divide. When the resulting syncline is superimposed on the well-known Raymond anticline, a double-peaked Raymond bump is formed. Furthermore, to each side of the Raymond bump, flanking synclines are formed. In addition, anisotropic effects are found to give rise to a subtle concavity in the surface profile to both sides of the summit. The lower center syncline, the flanking synclines, and the near-summit surface concavity have all previously been observed in nature, but hitherto no explanation for the genesis of these features has been given. We compare modeling results with radiograms collected from Fuchs Ice Piedmont and Kealey Ice Rise, Antarctica. Good overall agreement is found. In particular, we are able to reproduce all observed qualitative features of surface geometry and internal layering by including, and only by including, the effects of induced nonlinear rheological anisotropy on flow. Rheological anisotropy has the potential to profoundly affect the age distribution with depth, and caution must be exercised when estimating age of ice from ice cores with an isotropic model. The occurrence of linear features parallel to the ridge of ice divides, often seen in satellite imagery, is indicative of long-term stability rather than signs of ongoing ice divide migration as previously suggested. Such ice divides are ideal locations for extracting ice cores.

Citation: Martín, C., G. H. Gudmundsson, H. D. Pritchard, and O. Gagliardini (2009), On the effects of anisotropic rheology on ice flow, internal structure, and the age-depth relationship at ice divides, J. Geophys. Res., 114, F04001, doi:10.1029/2008JF001204.

\section{Introduction}

[2] The rheology of ice crystals is strongly anisotropic and the orientation of crystal fabric of most ice of the polar ice sheets has been known for some time to be nonrandom [e.g., Paterson, 1994, pp. 99-102], yet in most flow modeling of ice masses, ice is currently treated as an isotropic material. There are flow situations where treating ice as an isotropic rheological material may well be justified. For example, where ice fabric is fully evolved and does not vary spatially over the region of interest, the effects of anisotropy can be emulated, to some degree, by introducing a suitable modified enhancement factor. In other situations, ignoring anisotropy cannot be so easily justified. At ice divides, for example, the ice fabric evolves from being

\footnotetext{
${ }^{1}$ Physical Sciences Division, British Antarctic Survey, Natural Environment Research Council, Cambridge, UK.

${ }^{2}$ Laboratoire de Glaciologie et de Géophysique de l'Environnement, UJF-Grenoble I, CNRS, Saint Martin d'Hères, France.

Copyright 2009 by the American Geophysical Union. 0148-0227/09/2008JF001204
}

isotropic at the surface where the snow is deposited, to being strongly anisotropic closer to the base [e.g., Alley et al., 1995; Gow et al., 1997; Thorsteinsson et al., 1997]. Here we use flow modeling to investigate how flow at and around ice divides, areas of key interest in glaciology, is affected by anisotropy.

[3] Ice divides of large ice sheets and ice caps are generally considered to be ideally suited as locations for extracting ice cores to study past climate. This follows from the expectation that horizontal velocity and horizontal shear are both close to zero for a stationary ice divide. The ice stratigraphy at an ice divide is therefore not expected to be significantly distorted by horizontal shear. Furthermore, an ice core extracted from a stationary ice divide will sample ice along a flow line, and depositional age can be expected to increase monotonically with depth.

[4] Being able to model accurately ice flow at ice divides is important for several reasons. When more direct methods, such as layer counting, cannot be used, dating of ice cores must be done using flow models. Recognizing, and being able to interpret correctly, signatures of nonstationary flow from internal structures detected by deep-penetrating radars 


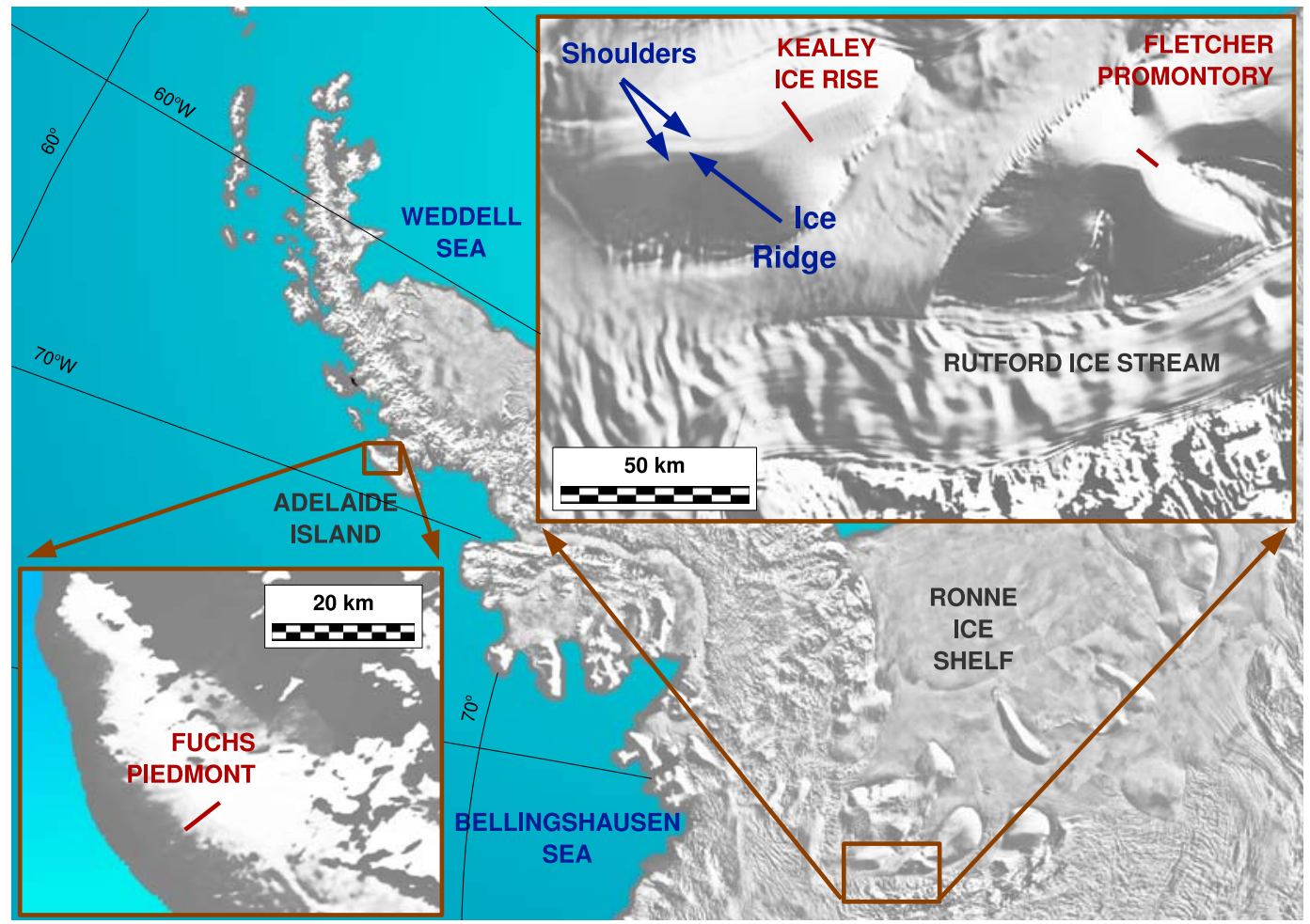

Figure 1. MODIS Mosaic of Antarctica (MOA) image map [Haran et al., 2005] showing the Antarctic Peninsula and the Ronne Ice Shelf area. The ice divide areas considered in this study are enlarged in the insets: Fuchs Piedmont (Adelaide Island) and Kealey Ice Rise and Fletcher Promontory (Ronne Ice Shelf area). The thick red lines are the profiles of the radargrams shown in Figure 2. Notice the concave shoulders (dips) parallel to the ridge in Kealey Ice Rise divide (highlighted by blue arrows), in Fletcher Promontory triple junction, and in Fuchs Piedmont ice divide.

represents a further incentive for understanding flow at ice divides. Flow modeling of ice divides is, however, a challenging task. In these regions, commonly used zerothorder models of large-scale ice sheet flow cannot be used [Hutter, 1983]. The flow regime at an ice divide changes from being characterized by vertical compression and concomitant horizontal extension at the divide, to that of predominantly horizontal shear beneath the flanks. Consequently, in general, all deviatoric stress components are of importance and a higher-order model [e.g., Mangeney and Califano, 1998], that considers longitudinal stresses, or a full-system Stokes model must be used. In addition, isotropic nonlinear rheology effects are known to significantly modify flow at ice divides [Raymond, 1983].

[5] In one of the first numerical studies of ice divides, Raymond [1983] showed that non-Newtonian effects give rise to a mechanically stiff zone of ice underneath the ridges of ice divides. This stiff zone of ice leads to the formation of anticlines, i.e., an upward wrapping of isochrones. These anticlines, now generally referred to as Raymond bumps, were subsequently found in radargrams collected at ice divides [e.g., Nereson et al., 1998b; Vaughan et al., 1999; Conway et al., 1999]. In radargrams, a vertical series of Raymond bumps are commonly seen, with one Raymond bump on the top of another forming a Raymond stack. The discovery of Raymond stacks gave an added impetus for measuring and modeling isochronal layers at ice divides. Ice divide migration causes a misalignment of the Raymond bumps with depth. Measurement of isochrone geometry with deep-penetrating radars coupled with ice flow modeling can, therefore, be used to infer past changes in ice divide position [Nereson et al., 1998b; Martín et al., 2006, 2009].

[6] Recent numerical modeling work has shown that anisotropy caused by nonrandom crystal fabric has the potential to significantly modify the size and shape of the Raymond bumps. In combination with a nonlinear flow law, anisotropy can cause a two-fold increase in the amplitude of the Raymond bumps [Pettit et al., 2007]. This suggests that any quantitative modeling of Raymond stacks requires the use of anisotropic flow laws.

[7] An indication that our understanding of the characteristics of flow at ice divides is still not complete comes from the fact that flow models have hitherto not been able to reproduce a number of observed qualitative features of radargrams and surface profiles from ice divides. One such qualitative aspect of ice divide dynamics is the appearance of linear features seen in satellite images of ice divides, to one or both sides, of the ice divide ridge. Examples of this feature are given in Figure 1 showing MODIS images of Kealey Ice Rise and Fletcher Promontory, in the Ronne Ice Shelf area, and Fuchs Piedmont, on Adelaide Island. Goodwin and Vaughan [1995] showed that such features in visible imagery are expressions of subtle concavity in the surface profile. Hence, on some ice divides there is a region, to one or both sides of the crest, where the surface profile is concave-up. This surface concavity contrasts strongly with 


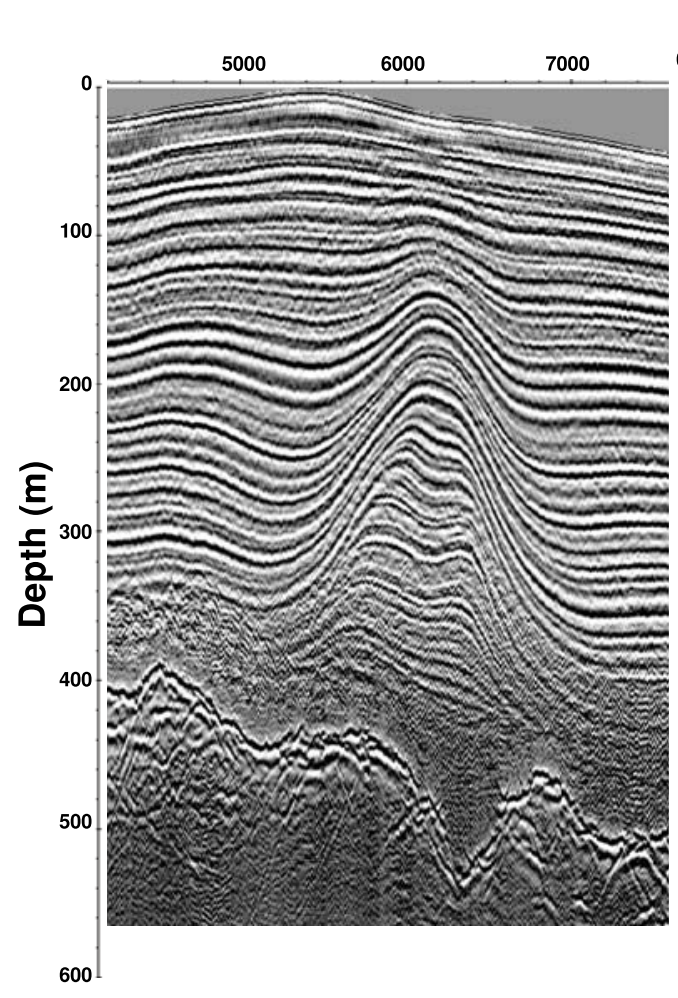

a) Fuchs Piedmont

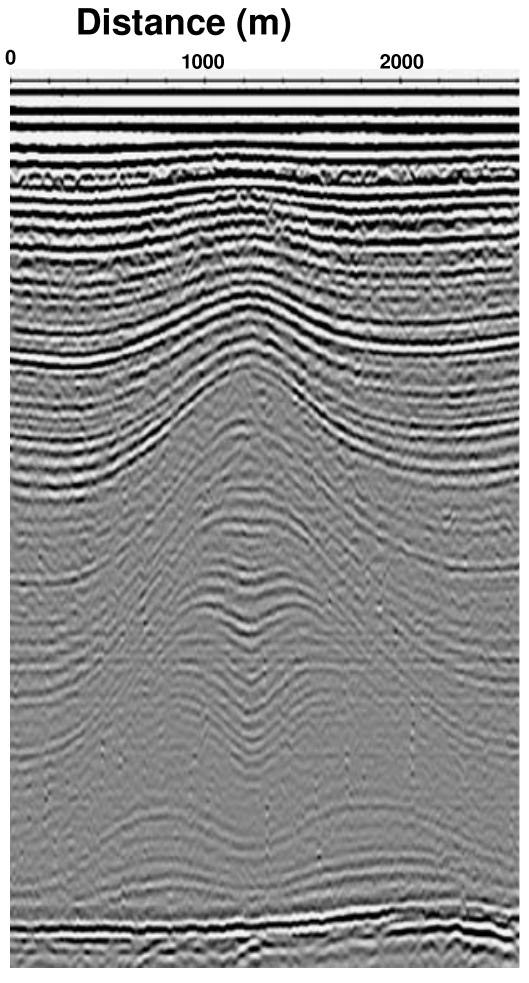

b) Fletcher Promontory

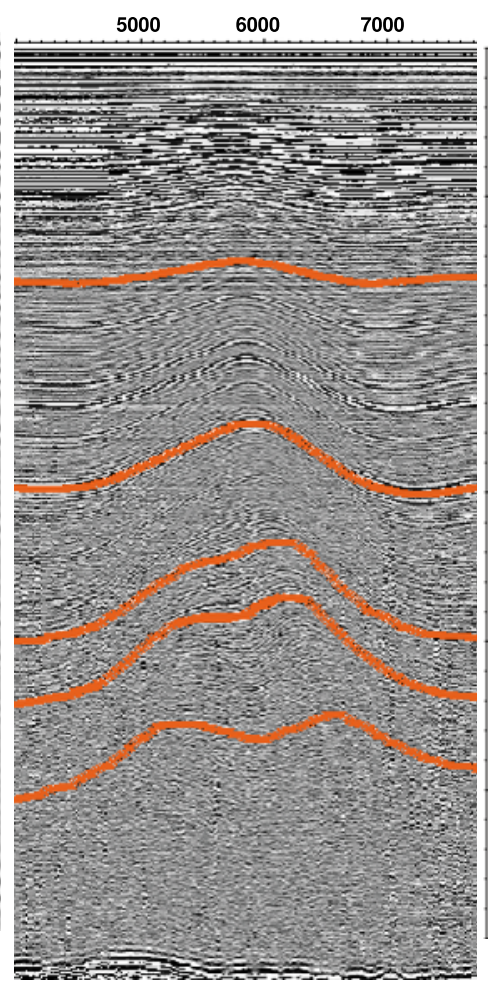

c) Kealey Ice Rise

Figure 2. Radargrams of (a) Fuchs Piedmont, (b) Fletcher Promontory, and (c) Kealey Ice Rise. The radargrams were collected by H. Pritchard (Fuchs Piedmont), R. C. A. Hindmarsh (Fletcher Promontory), and G. H. Gudmundsson (Kealey Ice Rise).

the general convex-up shape of an ice divide. The resulting geometrical shape of the surface profile in the vicinity of the ice divide is that of concave shoulders. Goodwin and Vaughan [1995] did not offer an explanation for the genesis of the concave shoulders, but concluded that they were not compatible with known aspects of steady state ice divide dynamics, and might therefore be caused by some transient effects such as an ongoing ice divide migration.

[8] Another poorly understood feature of ice divide flow is the occurrence of convex troughs, i.e., synclines, in isochrones to both sides of the Raymond bumps. Examples of such flanking synclines within the Raymond stack are seen in all three radargrams shown in Figure 2 from Kealey Ice Rise, Fletcher Promontory and Fuchs Piedmont (see location map in Figure 1). Usually the flanking synclines are most clearly seen over the depth range from about $1 / 3$ to $2 / 3$ of the total ice thickness. Parrenin and Hindmarsh [2007] show that by assuming certain types of velocity fields, synclines in isochronal layers on both sides of the Raymond bumps can be formed. Parrenin and Hindmarsh [2007] did not attempt to explain why the spatial variation in the velocity field around ice divides is sometimes of the type needed for the flanking synclines to be formed. Pettit et al. [2007] give examples of numerically calculated isochrones showing both the Raymond anticline and, to both sides, two smaller synclines [Pettit et al., 2007, Figure 7]. Pettit et al. [2007] find that the flanking synclines are only produced when effects of both anisotropy due to crystal fabric and the effects of deviatoric stresses on effective viscosity are included.

[9] A further interesting feature sometimes seen in radargrams from ice divides is the occurrence of a downward curving fold (syncline) in the central lower part of the ice divide region. Three examples of such synclines can be seen in Figure 2. When the central lower part of the syncline is superimposed on the larger central anticline, the resulting geometrical structure is a double-peaked Raymond bump. To date no explanation has been put forward for the existence of double-peaked Raymond bumps. Doublepeaked Raymond bumps were first found independently by R. C. A. Hindmarsh and G. H. Gudmundsson in radargrams from Fletcher Promontory and Kealey Ice Rise, respectively, collected in Antarctic field season 20052006. Subsequently, it has been discovered that they are common features of radargrams from ice divides (R. Bingham, personal communication, 2008).

[10] Figure 3 gives a graphical summary of the various qualitative features seen in the three radargrams of Figure 2.

[11] This study focuses on the modeling of flow, internal layering, and surface topography of ice divides. We aim to identify and elucidate the mechanisms responsible for a number of the distinctive and characteristic qualitative features commonly found in radargrams from these areas. In particular, we investigate the modifications in flow around ice divides due to induced rheological anisotropy of polycrystalline ice. We calculate the evolution of ice 


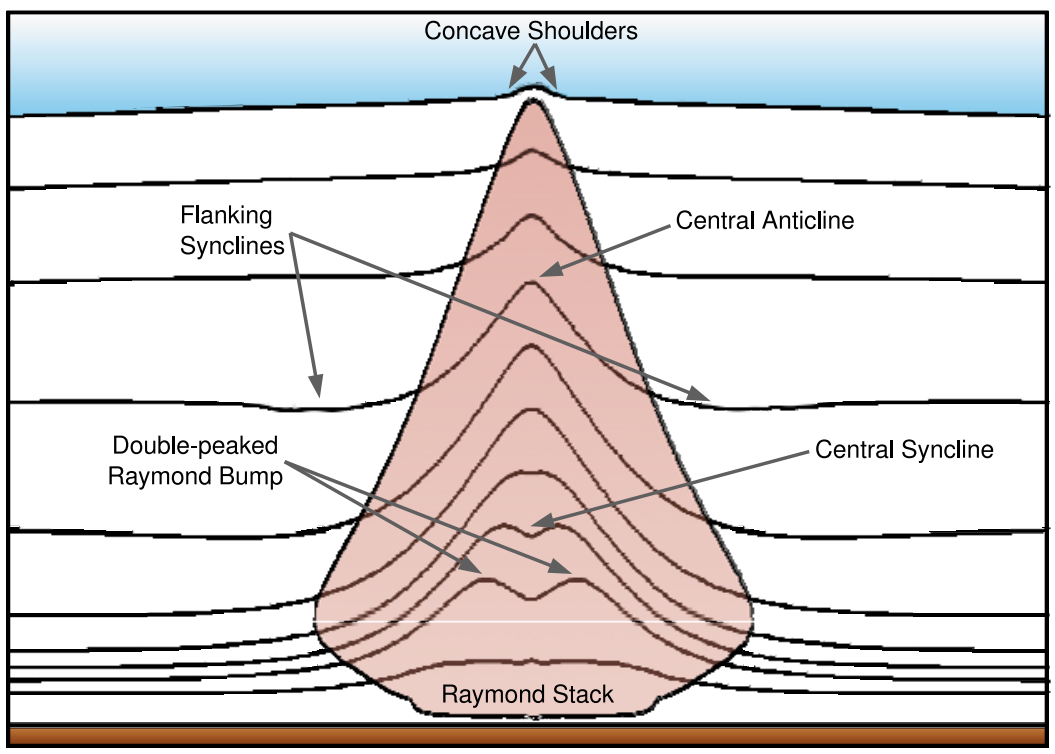

Figure 3. Generalized stratigraphy of an ice divide.

fabric from an initial isotropic state at the surface using a strain-induced fabric evolution model proposed by GilletChaulet et al. [2006]. The constitutive law used in this study includes the effects of ice fabric and deviatoric stresses on the effective (anisotropic) viscosity distribution. We find that by including the effects of nonrandom ice fabric on flow, we can successfully reproduce all qualitative features of surface topography and internal layering listed above. Our modeling approach is generic and not focused on one particular ice divide, but rather tries to identify the general aspect of ice divide flow.

\section{Governing Equations and Numerical Model}

\subsection{Field Equations and Boundary Conditions}

[12] We solve flow in an $x-z$ plane orthogonal to the axis of an ice divide. The $z$ axis is aligned vertically. The ice surface and bed are given by $z=s(x, t)$ and $z=b(x)$, respectively.

[13] The field and the boundary equations are

$$
\begin{aligned}
& \partial_{x} u+\partial_{z} w=0, \quad b(x) \leq z \leq s(x, t), \\
& \left.\begin{array}{l}
\partial_{x} \sigma_{x x}+\partial_{z} \sigma_{x z}=0 \\
\partial_{x} \sigma_{x z}+\partial_{z} \sigma_{z z}=\rho g
\end{array}\right\}, \quad b(x) \leq z \leq s(x, t) \\
& \partial_{t} s+u \partial_{x} s=w+a, \quad z=s(x, t), \\
& \boldsymbol{\sigma} \cdot \boldsymbol{n}=\mathbf{0} \quad z=s(x, t), \\
& u=w=0, \quad z=b(x) .
\end{aligned}
$$

[14] Equation (1a) expresses the conservation of mass, and equation (1b) the conservation of momentum. Here $\sigma$ is the Cauchy stress tensor, $\rho$ is the density of ice, $\mathbf{g}=g(0,0$,
$-1)$ is the gravitational acceleration vector, and $\boldsymbol{v}=(u, v, w)$ is the velocity vector. Equation (1c) is the free surface kinematic condition, where $a$ is accumulation rate of ice, expressed as a volume rate per unit area. Equations (1d) and (1e) are the boundary conditions at the surface and bed, respectively.

[15] Along the vertical boundaries of the model, the velocity variation with depth is assumed to follow the theoretical profile for isotropic laminar flow [e.g., Van der Veen, 1999, section 5.1]. Ice flux through the vertical boundaries is prescribed to be equal to the total surface accumulation, ensuring that the volume of ice within the modeling domain does not change with time. Following Hvidberg [1996] we use a numerical domain extending 20 times the divide thickness at each flank but restrict our analysis to a region extending only 10 times the divide thickness at each flank.

[16] Isochrones are lines connecting ice particles with equal age, where age is calculated from

$$
\begin{gathered}
\partial_{t} \Psi+u \partial_{x} \Psi+w \partial_{z} \Psi=1, \quad b(x) \leq z \leq s(x, t), \\
\Psi=0, \quad z=s(x, t),
\end{gathered}
$$

where $\Psi$ is the age.

[17] Although temperature can be expected to modify the ice flow regime by affecting the ice viscosity, basal conditions (melting and sliding) and ice recrystallization processes, we limit the discussion here to the isothermal case. The justification for doing so comes from a preliminary study where the effects of temperature on ice flow, divide geometry, and internal layering were estimated and found to be of comparatively little importance. It is not difficult to understand why the temperature plays a rather insignificant role in modifying flow. The ice divides considered in this study (Kealey Ice Rise, Fletcher Promontory and Fuchs Piedmont) are thin (450-600 m) and with high accumula- 
Table 1. Characteristic Time for Different Ice Divides and the Equivalent Time for the Different Stages Presented in Figures 4-6

\begin{tabular}{|c|c|c|c|c|c|c|c|}
\hline & $\begin{array}{c}\mathrm{a} \\
(\mathrm{m} / \mathrm{yr}) \\
\end{array}$ & $\begin{array}{r}H \\
(\mathrm{~m}) \\
\end{array}$ & $\begin{array}{c}t_{D} \\
(\mathrm{kyr})\end{array}$ & $\begin{array}{c}1 / 10 t_{D} \\
(\mathrm{kyr})\end{array}$ & $\begin{array}{c}t_{D} \\
(\mathrm{kyr})\end{array}$ & $\begin{array}{l}4 t_{D} \\
(\mathrm{kyr})\end{array}$ & $\begin{array}{r}10 t_{D} \\
(\mathrm{kyr}) \\
\end{array}$ \\
\hline Fuchs Piedmont & $0.98^{\mathrm{a}}$ & 450 & 0.46 & 0.05 & 0.46 & 1.83 & 4.6 \\
\hline Fletcher Promontory & $0.44^{\mathrm{a}}$ & 600 & 1.36 & 0.14 & 1.36 & 5.44 & 13.6 \\
\hline Roosevelt Island $^{\mathrm{b}}$ & 0.18 & 700 & 3.8 & 0.38 & 3.8 & 15.2 & 38 \\
\hline Siple Dome ${ }^{c}$ & 0.1 & 1000 & 10 & 1 & 10 & 40 & 100 \\
\hline
\end{tabular}

${ }^{\mathrm{a}}$ Arthern et al. [2006].

${ }^{\mathrm{b}}$ Conway et al. [1999].

${ }^{\mathrm{c}}$ Nereson and Waddington [2002]

${ }^{\mathrm{d}}$ Gillet-Chaulet [2007].

tion rate $(0.5-1.0 \mathrm{~m} / \mathrm{yr})$ (see Table 1$)$. Estimating the difference in surface and basal temperature using the Robin solution [Robin, 1955] gives temperature differences of only $4.5^{\circ} \mathrm{C}, 7.4^{\circ} \mathrm{C}$ and $7.8^{\circ} \mathrm{C}$ for Kealey Ice Rise, Fletcher Promontory and Fuchs Piedmont, respectively. Moreover, basal temperatures are found to be well below the melting point $\left(-22.5^{\circ} \mathrm{C},-19.6^{\circ} \mathrm{C}\right.$ and $-5.4^{\circ} \mathrm{C}$ ). (Accumulation rates are from Arthern et al. [2006] and surface temperatures are from Comiso [2000].) We will discuss further the recrystallization processes in section 2.3 and the limitations of the isothermal assumption in section 4 .

\subsection{Rheology}

[18] Several anisotropic ice rheologies have been proposed in the past [e.g., Lliboutry, 1993; Castelnau et al., 1996; Mangeney et al., 1997; Thorsteinsson, 2001; Gödert, 2003; Gillet-Chaulet, 2007; Pettit et al., 2007; Castelnau et $a l ., 2008]$. All these models differ in various details with regards to the crystal model used (Schmid law, a basal slip system model, transversely isotropic), the description of the fabric (discrete or continuous through an orientation distribution function or an orientation tensor) and in the homogenization procedure used (uniform strain rate, uniform stress or intermediate self-consistent procedures). For a detailed review of all these models, the reader can refer to Gagliardini et al. [2009].

[19] To describe the ice fabric we use the orientation tensors [e.g., Gödert, 2003; Gillet-Chaulet et al., 2006]. In spherical coordinates these can be written as

$$
\begin{aligned}
& a_{i j}^{(2)}=\left\langle c_{i} c_{j}\right\rangle=\frac{1}{2 \pi} \int_{0}^{\pi / 2} \int_{0}^{2 \pi} f(\theta, \phi)\left(c_{i} c_{j}\right) \sin \theta d \theta d \phi, \\
& a_{i j k l}^{(4)}=\left\langle c_{i} c_{j} c_{k} c_{l}\right\rangle=\frac{1}{2 \pi} \int_{0}^{\pi / 2} \int_{0}^{2 \pi} f(\theta, \phi)\left(c_{i} c_{j} c_{k} c_{l}\right) \sin \theta d \theta d \phi,
\end{aligned}
$$

where $f(\theta, \phi)$ is the probability distribution of finding the $c$ axes, represented with the normalized vector $\boldsymbol{c}$, in the interval $([\theta, \theta+d \phi],[\phi, \phi+d \phi])$. The function $f(\theta, \phi)$ is known as the orientation distribution function (ODF).

[20] Here we assume that the monocrystal grain behaves as a viscous transversely isotropic medium and that there is a uniform stress distribution within the polycrystal (uniform stress or static model) [e.g., Gödert, 2003; Thorsteinsson, 2001; Gagliardini and Meyssonnier, 1999]. And following Gödert [2003] and Gillet-Chaulet et al. [2005], we write the orthotropic rheology of the polycrystal as

$$
\begin{aligned}
\boldsymbol{D}= & \frac{1}{2 \eta_{0}}\left(\beta \boldsymbol{S}+\lambda_{1} \boldsymbol{a}^{(4)}: \boldsymbol{S}+\lambda_{2}\left(\boldsymbol{S} \cdot \boldsymbol{a}^{(2)}+\boldsymbol{a}^{(2)} \cdot \boldsymbol{S}\right)\right. \\
& \left.+\lambda_{3}\left(\boldsymbol{a}^{(2)}: \boldsymbol{S}\right) \boldsymbol{I}\right)
\end{aligned}
$$

where $\boldsymbol{D}$ and $\boldsymbol{S}$ denote the strain rate and deviatoric stress tensors, respectively $\left(\boldsymbol{S}=\boldsymbol{\sigma}-P \boldsymbol{I} ; P=\frac{1}{3} \sigma_{i i}\right)$. The symbols . and : denote the contracted product and the double contracted product, respectively, and $\boldsymbol{I}$ is the identity matrix. The three $\lambda$ symbols are defined as

$$
\lambda_{1}=2\left(\beta \frac{\gamma+2}{4 \gamma-1}-1\right), \lambda_{2}=(1-\beta) \text { and } \lambda_{3}=-\frac{1}{3}\left(\lambda_{1}+2 \lambda_{2}\right) .
$$

[21] The mechanical properties of the monocrystal can then be described by the basal shear viscosity $\eta_{0}$, and the two relative viscosities $\beta$, the ratio of viscosity of the grain for shear parallel to the basal plane to that in the basal plane, and $\gamma$, the ratio of the viscosity in compression or tension along the $c$ axis to that in the basal plane [e.g., Lliboutry, 1987; Meyssonnier and Philip, 1996]. The rheological parameter $\beta$ is known to be significantly smaller than unity, and the parameter $\gamma$ to be close to unity [Gillet-Chaulet et al., 2006]. Here we use the values $\beta=10^{-2}$ and $\gamma=1$. Our numerical experiments, not reported here, show that results are not sensitive to the exact values of the parameters $\beta$ and $\gamma$.

[22] By similarity with Glen's flow law, we propose a nonlinear extension of the rheology described in equation (4) where

$$
\eta_{0}=\frac{1}{2} A^{-\frac{1}{n}}\left(\frac{1}{2} \operatorname{tr}\left(\boldsymbol{D}^{2}\right)^{\frac{1-n}{2 n}}\right)
$$

where $A$ is the rate factor, $n$ the rheological index and ' $\operatorname{tr}()$ ' denotes trace. This nonlinear extension is similar to that used by Pettit [2003].

[23] As discussed in section 2 we consider the ice to be isothermal and the value of the rate factor $A$ used in equation (5) is assumed to be constant. 


\subsection{Fabric Evolution}

[24] We assume that recrystallization processes do not occur and that the ice fabric is induced by deformation. In that case, following Gödert [2003] and Gillet-Chaulet et al. [2006] the evolution of the second-order orientation tensor $\boldsymbol{a}^{(2)}$ can be written as

$$
\frac{D \boldsymbol{a}^{(2)}}{D t}=\boldsymbol{W} \boldsymbol{a}^{(2)}-\boldsymbol{a}^{(2)} \boldsymbol{W}-\left(\boldsymbol{C} \boldsymbol{a}^{(2)}+\boldsymbol{a}^{(2)} \boldsymbol{C}\right)+2 \boldsymbol{a}^{(4)}: \boldsymbol{C},
$$

where $\boldsymbol{W}$ is the spin tensor (the skew symmetric part of the gradient tensor),

$$
\boldsymbol{C}=(1-\alpha) \boldsymbol{D}+\alpha \frac{1}{2 \eta_{0}} \boldsymbol{S}
$$

and $\alpha$ is the interaction parameter. The interaction parameter $\alpha$ controls the relative weighting of the strain rate tensor $(\boldsymbol{D})$ and the deviatoric stress tensor $(\boldsymbol{S})$ in the fabric evolution equation (equation (6)).

[25] As a boundary condition we assume isotropic ice at the surface, i.e.,

$$
\boldsymbol{a}^{(2)}=\frac{1}{3} \boldsymbol{I}
$$

for $z=s(x, t)$.

[26] Gödert [2003] argues that the interaction parameter $\alpha$ is a monotonic function of the degree of alignment of the $c$ axes and should be taken as zero for completely aligned $c$ axes. Gillet-Chaulet et al. [2006], using an identical evolutionary equation from that used here and a similar model of ice anisotropy but assuming linear rheology, find that using $\alpha=0.06$ allows accurate reproduction of fabric evolution when compared with a VPSC model (viscoplastic self-consistent model). Durand et al. [2007], using the same model as Gillet-Chaulet et al. [2006], find a good accordance with EPICA Dome C core data using $\alpha=0.01$.

[27] The sensitivity of our numerical results to the exact value of $\alpha$ was tested in a series of runs. We found numerical results to be effectively independent of the value of $\alpha$ as long as $\alpha$ is chosen to be small $(<0.1)$. For simplicity, therefore, we only report here results of runs using $\alpha=0$. In effect, the transient evolution of the secondorder orientation tensor used here therefore only depends on the symmetric and skew symmetric part of the velocity gradient tensor and the fourth-order orientation tensor (see equation (6)).

[28] From ice core texture and microstructure measurements, it is known that ice recrystallization is important in the fabric development. The most significant recrystallization processes that occur in ice divides are rotation recrystallization and migration recrystallization. The effects of the former manifest typically below a certain depth (e.g., below $200 \mathrm{~m}$ at Siple Dome [Diprinzio et al., 2005], bellow $400 \mathrm{~m}$ at Byrd ice core [Alley et al., 1995] and below $650 \mathrm{~m}$ at GRIP ice core [Thorsteinsson et al., 1997]) and is related with the formation of (sub)grain boundaries due to heterogeneous loading, the latter occurs at the warm base of the divide and is characterized by a very fast grain growth [e.g., Gagliardini et al., 2009]. As the ice divides considered in this study are thin $(450-600 \mathrm{~m})$ and, as discussed in section 2.1, the basal temperatures are expected to be below the melting point, we can assume that the influence of recrystallization processes in these divides is small compared with the fabric development induced by deformation. The influence of recrystallization is discussed in section 4 .

\subsection{Closure Approximation}

[29] The evolution of the second-order orientation tensor $a^{(2)}$ given by equation (6) depends on $\boldsymbol{a}^{(4)}$, and for that reason the system of equations is not yet closed. A common approach of obtaining a closed system is to express the components of the fourth-order orientation tensor as functions of those of the second-order orientation tensor [e.g., Advani and Tucker, 1990]. We follow this approach and use the invariant-based closure approximation (IBOF) proposed by Gillet-Chaulet et al. [2006]. As shown by Chung and Kwon [2002], the general form of the IBOF closure approximation is

$$
\begin{aligned}
a_{i j k l}^{(4)}= & \beta_{1} \operatorname{Sym}\left(\delta_{i j} \delta_{k l}\right)+\beta_{2} \operatorname{Sym}\left(\delta_{i j} a_{k l}^{(2)}\right)+\beta_{3} \operatorname{Sym}\left(a_{i j}^{(2)} a_{k l}^{(2)}\right) \\
& +\beta_{4} \operatorname{Sym}\left(\delta_{i j} a_{k m}^{(2)} a_{m l}^{(2)}\right)+\beta_{5} \operatorname{Sym}\left(a_{i j}^{(2)} a_{k m}^{(2)} a_{m l}^{(2)}\right) \\
& +\beta_{6} \operatorname{Sym}\left(a_{i m}^{(2)} a_{m j}^{(2)} a_{k n}^{(2)} a_{n l}^{(2)}\right),
\end{aligned}
$$

where 'Sym' denotes the symmetrical part of its argument and $\beta_{i}$ are six functions of the second and third invariants of $\boldsymbol{a}^{(2)}$. Following Chung and Kwon [2002], Gillet-Chaulet et al. [2006] assume that $\beta_{i}$ are polynomials of degree 5 in the second and third invariant of $\boldsymbol{a}^{(2)}$, and compute the resulting coefficients so that $\boldsymbol{a}^{(4)}$ given by equation (9) fits the fourthorder orientation tensor given by the ODF proposed by Gagliardini and Meyssonnier [1999].

\subsection{Nondimensionalization}

[30] Results are presented in nondimensionalized form using the nondimensional procedure of Martin et al. [2009], i.e.,

$$
\begin{aligned}
(x, z) & =H(\hat{x}, \hat{z}), \\
(u, w) & =a(\hat{u}, \hat{w}), \\
\boldsymbol{D} & =\frac{a}{H} \hat{\boldsymbol{D}}, \\
(\boldsymbol{S}, P) & =\left(\frac{a}{A H}\right)^{\frac{1}{n}}(\hat{\boldsymbol{S}}, \hat{P}) .
\end{aligned}
$$

Nondimensional variables are denoted by placing a caretshaped symbol on the top of their dimensional counterpart. The time variable is nondimensionalized using the characteristic time

$$
t_{D}=H / a
$$

of the divide, i.e.,

$$
t=t_{D} \hat{t}
$$

where $H$ is the thickness at the ice divide and $a$ the accumulation rate. 

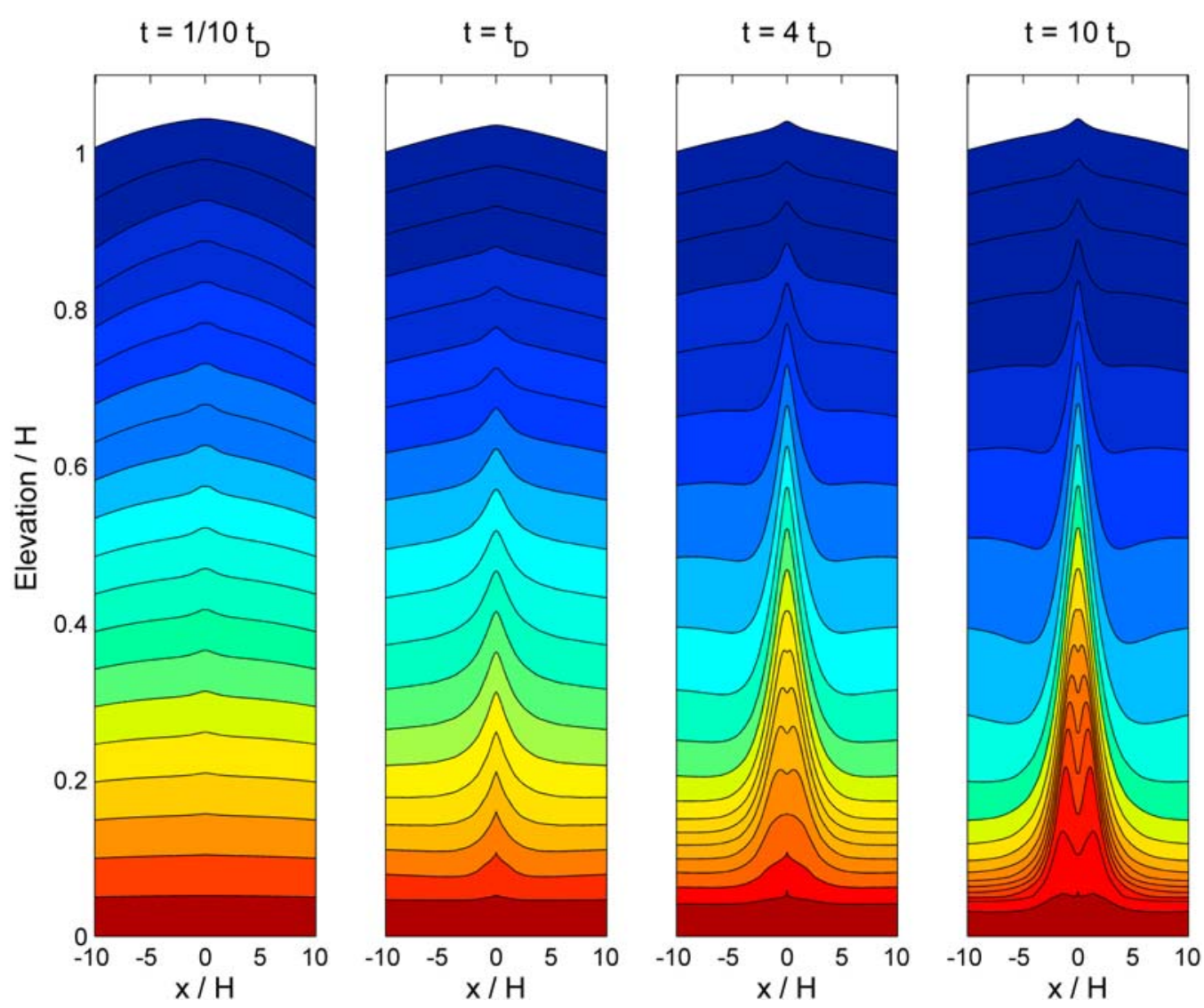

Figure 4. The modeled ice stratigraphy (isochrones) at different stages of the divide development.

\subsection{Numerical Scheme}

[31] For a given fabric and a given surface, we calculate the viscosity as described in Appendix $\mathrm{C}$ and solve the Stokes system (equations (1a) and (1b)). Once the ice velocity is known, we determine the evolution of the surface and ice fabric according to equations (1c) and (6).

[32] We solve the Stokes system using finite element methods, while semi-Lagrangian methods are used to solve the equations for the free surface evolution, fabric evolution and age. The numerical technique is described for isotropic ice by Martín [2003] and Martín et al. [2003, 2006, 2009]. The modifications to that method needed for anisotropic ice are described in Appendixes A and B.

\section{Results}

\subsection{Ice Divide Development Toward a Steady State}

[33] We aim to understand the development of ice flow and crystal fabric in ice divides. To this end, we model the evolution of an ice divide from the onset of divide flow toward a steady state.

[34] Initial conditions are isotropic ice and a flat surface over the whole model domain. A constant surface accumulation rate is prescribed. Ice is allowed to flow out from the left- and right-hand side margins of the domain at a rate that equals the surface influx of ice. In nondimensional units, both the initial thickness and the accumulation rate are equal to unity.

[35] Results corresponding to different stages of the ice divide development $\left(t=\{1 / 10,1,4,10\} t_{D}\right)$ are shown in
Figures $4,5,6$, and 7 . In these runs the stress exponent was set as $n=3$. The value of the rate factor $A$ used (see equation (5)) corresponds to an ice temperature of $-10^{\circ} \mathrm{C}$. However, the value of the rate factor does not significantly affect the overall transient evolution of the ice divide, which is determined by $t_{D}$. The rate factor has little effect on internal layering during the transient stage, and no effect on the steady state layering.

[36] Figure 4 shows isochrone positions as functions of time. For $t=0$ (not shown) the initial isochrones are aligned horizontally. With time, ice flow causes the oldest ice to be increasingly strongly located directly under the ridge of the ice divide. The Raymond bump is already visible for $t=t_{D} /$ 10 (see Figure 4) as a narrowly defined anticline. Figure 4 shows that the Raymond bumps start to grow at depth equal to about half ice thickness.

[37] With time, the amplitude of the Raymond bumps increases markedly. At $t=t_{D}$ the overall geometrical shape of the isochrones is no longer uniformly that of an anticline (see Figure 4). Close to the bed, the isochrones are concave up, while closer to the surface they are concave down. As a consequence, flanking synclines are formed close to the bed to both sides of the Raymond bumps.

[38] At $t=4 t_{D}$ the flanking synclines are seen over a greater range of depths and their amplitudes have grown. A slight downward curving (i.e., concave up) fold located at the center of some of the Raymond bumps also becomes visible in Figure 4.

[39] At $t=10 t_{D}$ the quasi steady state has been reached. As shown in Figure 4, in the lower parts of the ice column 

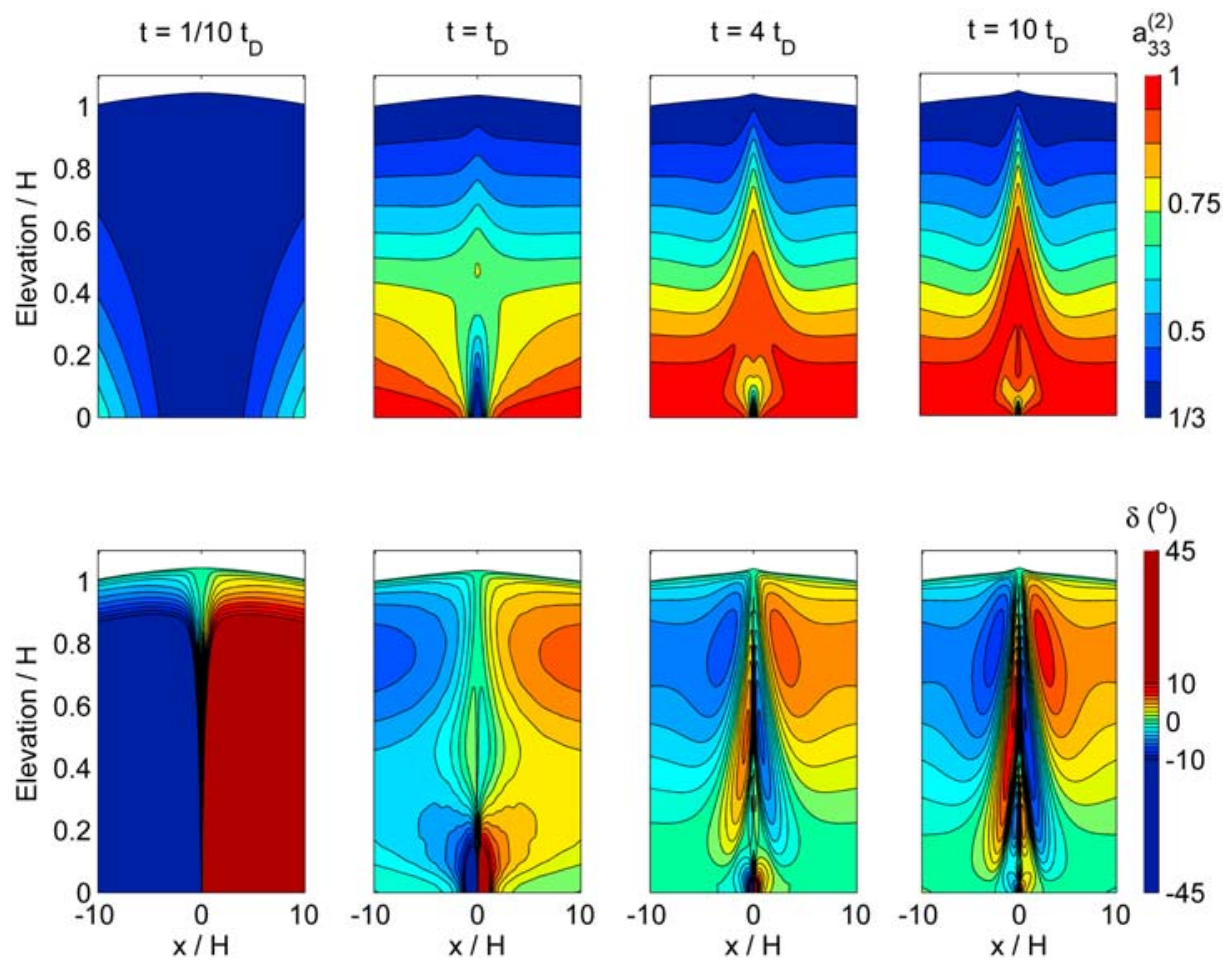

Figure 5. Contours of (top) $a_{33}^{(2)}$ and (bottom) $\delta$ at different stages of the divide development. Here $a_{33}^{(2)}$ is the maximum eigenvalue of the orientation tensor, varying from $1 / 3$ for isotropic ice to 1 for single maximum fabrics. Here $\delta$ is the angle in the divide plane between the reference and the orthotropic frame.


Figure 6. Contours of steady state (top) horizontal velocity $\hat{u}$ and (bottom) vertical velocity $\hat{w}$. The velocity fields shown have been nondimensionalized, using $(\hat{u}, \hat{w})=[a](u, w)$, where $a$ is the specific surface mass balance and $u$ and $w$ are the horizontal and vertical velocity components, respectively. Parameters used are the same as for Figure 4. 

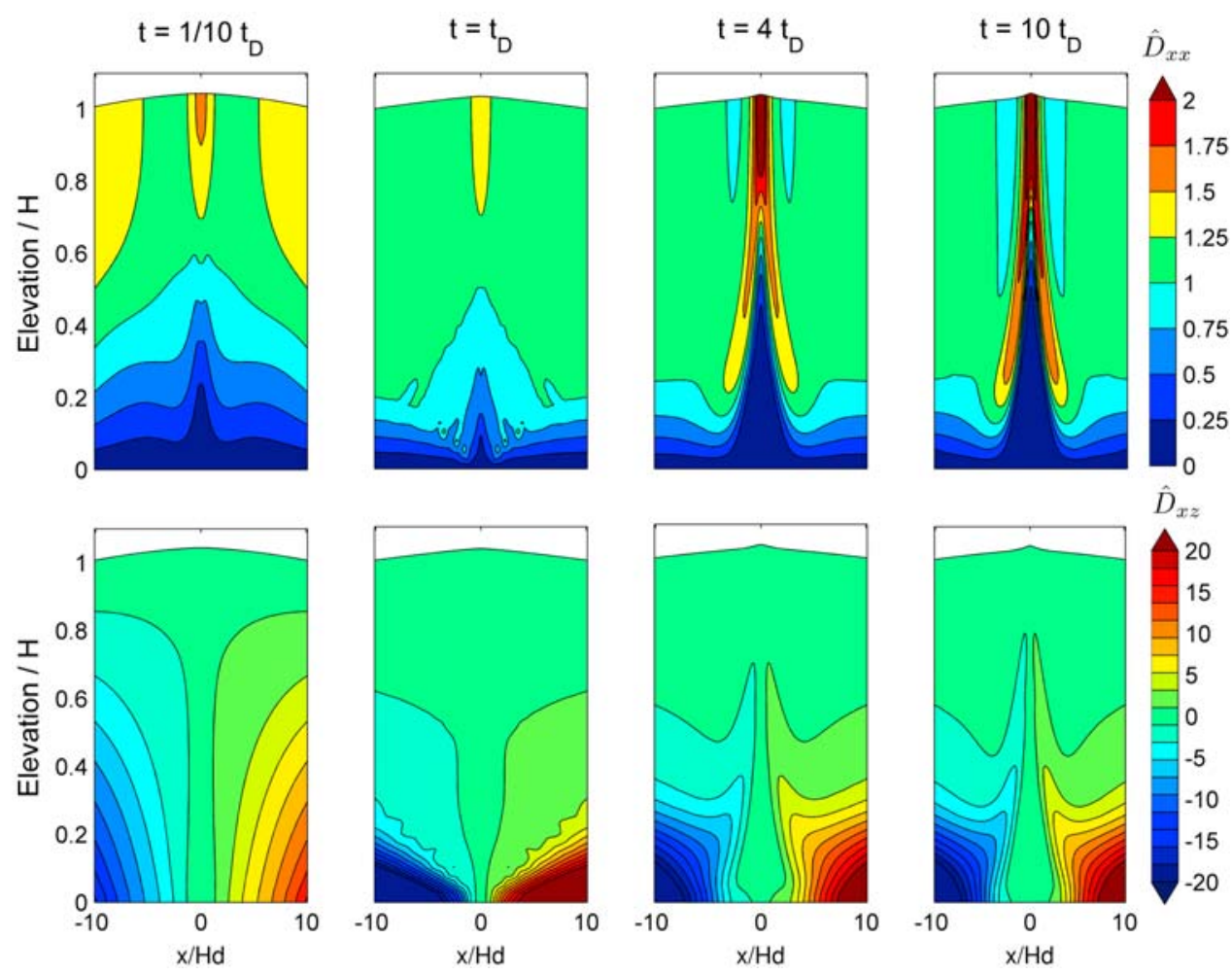

Figure 7. (top) Contours of horizontal strain rates $\hat{D}_{x x}$. (bottom) Contours of vertical shear rates $\hat{D}_{x z}$. The strain rates shown are nondimensional strain rates in the units of $a / H$, where $a$ is the specific surface mass balance and $H$ is the mean ice thickness.

the Raymond bumps are now double peaked, while further toward the surface the bumps are single peaked. In the middle part of the ice column, pronounced flanking synclines are seen.

[40] The evolution of the ice fabric is shown in Figure 5. Figure 5 (top) shows contour lines of the largest eigenvalue of the second-order orientation tensor $\left(a_{33}^{(2)}\right)$. This eigenvalue goes from $1 / 3$, for isotropic ice, to 1 for a single-maximum fabric. As Figure 5 (top) shows, the fabric is at $t=t_{D} / 10$ mostly isotropic. This is a simple consequence of the initial condition used in the run, where at $t=0$ the ice was prescribed as isotropic. With the onset of ice flow the fabric starts to evolve toward a more anisotropic state. At first, the most strongly anisotropic ice is found some distance away from the ice divide, close to the bed. With time, as the situation approaches a steady state, the most strongly anisotropic ice is concentrated directly below the divide (see Figure 5).

[41] In Figure 5 (top) showing $a_{33}^{(2)}$, a strongly localized zone of less developed fabric is found close to the bed and directly underneath the summit $(x=0)$ of the divide for $t \geq$ $t_{D}$. With time the size of this zone decreases, and as steady state is reached the zone collapses to a point and disappears. Hence, in steady state the value of $a_{33}^{(2)}$ increases monotonically with depth, with the most anisotropic ice concentrated close to the bed directly underneath the ice divide.

[42] Figure 5 (bottom) shows the evolution of the angle $(\delta)$ between the reference and the orthotropic frame in the $x-z$ plane. The orthotropic frame is defined as the local orthogonal coordinate system spanned by the eigenvectors of the (symmetric) second-order orientation tensor. For $t \geq$
$t_{D}$ the angle $\delta$ is close to zero in all the domain, meaning that the $c$ axis of the fabric is aligned in the vertical.

[43] The velocity field at quasi steady state is depicted in Figure 6. Horizontal and vertical velocities are shown for the time step $t=10 t_{D}$. Note that the velocity has been nondimensionalized by the accumulation rate and, consequently, the vertical velocity at the surface tends to be close to unity. A conspicuous feature of the vertical velocity field in Figure 6 (bottom) is the sharp and strongly localized reduction in velocity in the area below the ridge of the ice divide. This zone is seen for all time steps and, in Figure 6, gives rise to pronounced convex-up shaped contour lines. Note that the variation in vertical velocity with depth at $x=0$, differs significantly from that only a few ice thicknesses away. As compared to the situation just outside of the divide, the variation in vertical velocities with depth at the summit is considerably more concentrated toward the surface.

[44] The horizontal strain rates and vertical shear strain rates $\left(\hat{D}_{x x}\right.$ and $\left.\hat{D}_{x z}\right)$, are shown in Figure 7 (top) and Figure 7 (bottom), respectively. Note that because of the incompressibility of ice, $\hat{D}_{x x}=-\hat{D}_{z z}$ and the upper panel, therefore, can be considered to depict the vertical strain rates as well, albeit with an opposite sign. The largest rates of vertical compression are found close to the surface of the summit $(x=0)$, with (absolute) values decreasing with depth. Interestingly, for the lowest about $2 / 3$ of the ice column, maximal vertical strain rates are found off the vertical $x=0$ line, rather than directly below the summit.

[45] Figure 8 shows, the eigenvalues of the orientation tensor $\boldsymbol{a}^{(2)}$ as a function of depth below the ice divide 

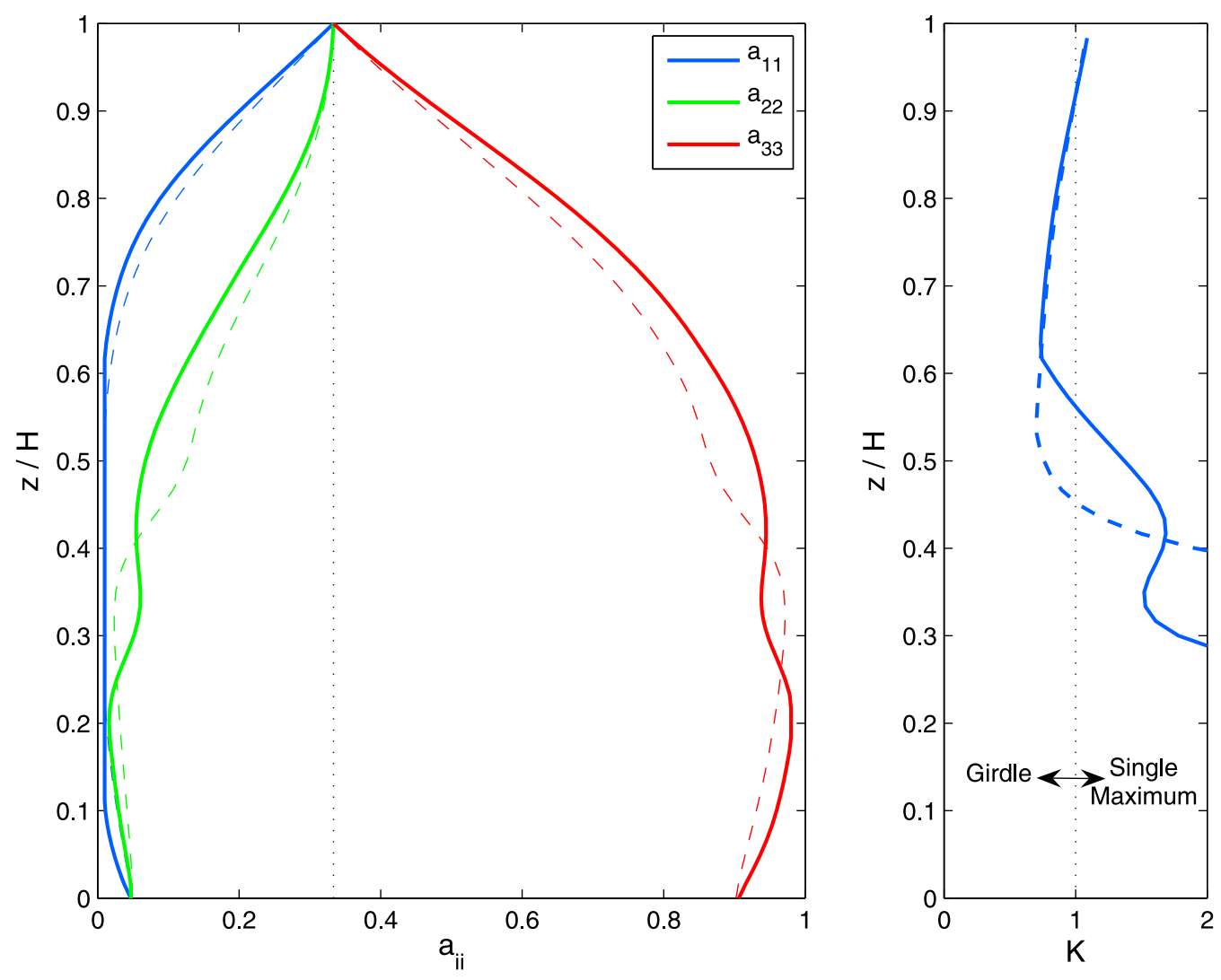

Figure 8. The eigenvalues of the orientation tensor $\boldsymbol{a}^{(2)}$ and the $K$ Woodcock value versus depth at the ice divide position at different stages of its evolution: $t=4 t_{D}$ (dashed lines) and $t=10 t_{D}$ (solid lines).

(Figure 8 , left), and the corresponding Woodcock $K$ value (Figure 8, right) [Woodcock, 1977] defined as

$$
K=\frac{\log \left(a_{33}^{(2)} / a_{22}^{(2)}\right)}{\log \left(a_{22}^{(2)} / a_{11}^{(2)}\right)}
$$

for $t=4 t_{D}$ (dashed lines) and $t=10 t_{D}$ (solid lines). As explained above, $t=10 t_{D}$ corresponds closely to a steady state situation.

[46] The Woodcock $K$ value can be used to distinguish single maximum ( $c$ axis aligned) and girdle fabrics ( $c$ axis clustered around a vertical plane) [Wang et al., 2002]. Values of $K$ between zero and one indicate a girdle fabric and those larger than one, a single maximum fabric.

[47] Figure 8 shows how the fabric varies from being isotropic at the surface, to a vertical girdle fabric in the upper part of the divide, to a strong single-maximum fabric toward the base. Just below the divide position $\delta=0$ (see Figure 5) and $a_{11}^{(2)}=a_{x x}^{(2)}, a_{22}^{(2)}=a_{y y}^{(2)}$ and $a_{33}^{(2)}=a_{z z}^{(2)}$. As Figure 8 shows, within the single-maximum zone the $c$ axes are aligned in the vertical, while in the girdle fabric zone the $c$ axes cluster around the $y z$ plane; that is, they are in the vertical plane along the axis of the divide.

[48] The fabric depicted in Figure 8 can be compared to fabric of ice cores such as the EPICA Dronning Maud Land ice core [Eisen et al., 2007, Figure 3], the NorthGRIP ice core from North Greenland [Wang et al., 2002, Figure 4], and the Siple Dome core from West Antarctica [Diprinzio et al., 2005, Figure 3]. As our modeling approach is generic and not focused on any particular ice divide we do not attempt any exact quantitative comparison with these ice cores. However, it should be noted that in all those ice cores the fabric changes from isotropic to girdle to single maximum with increasing depth, in general agreement with our model.

\subsection{Sensitivity Experiments}

[49] We now investigate the sensitivity of the results presented in section 3.1 to changes in model parameters and initial conditions.

\subsubsection{Sensitivity to Initial Conditions}

[50] In all the model runs shown above, the ice fabric was initially isotropic. We tested the sensitivity of the results to different initial ice fabric by calculating ice divide evolution starting with both random fabric and a single maximum fabric. The resulting development of the fabric is shown in Figure 9. For comparison, results for the isotropic case are also shown. In all cases the resulting steady state fabric is identical. From the time sequences shown in Figure 9, it is evident that the small differences seen for $t=10 t_{D}$ between the three cases, i.e., between isotropic (Figure 9, top), random (Figure 9, middle) and single maximum (Figure 9, bottom), are of transient nature.

\subsubsection{Sensitivity to Stress Exponent}

[51] The value of the stress exponent has a decisive effect on the resulting ice stratigraphy and ice fabric. This can be seen by comparing Figure 10 (top) with Figure 4 showing ice stratigraphy for $n=1$ and $n=3$, respectively. In Figures 10 

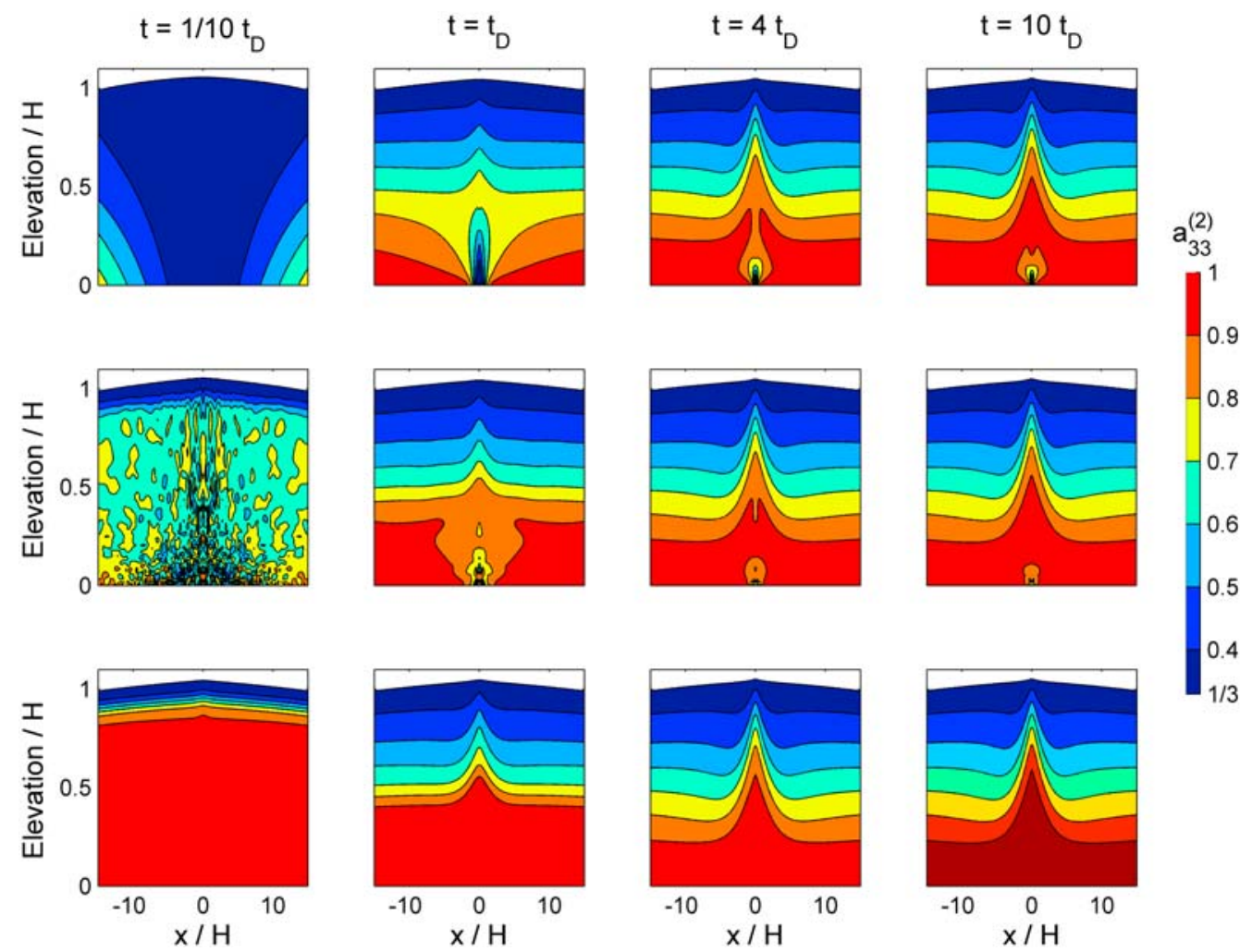

Figure 9. Sensitivity of fabric evolution to initial conditions. Contours of the maximum eigenvalue of the orientation tensor $\left(a_{33}^{(2)}\right)$ at different stages of the divide development $\left(t=\{1 / 10,1,4,10\} t_{D}\right)$ assuming three different fabric initial conditions: (top) isotropic ice, (middle) random fabric, and (bottom) single maximum fabric.
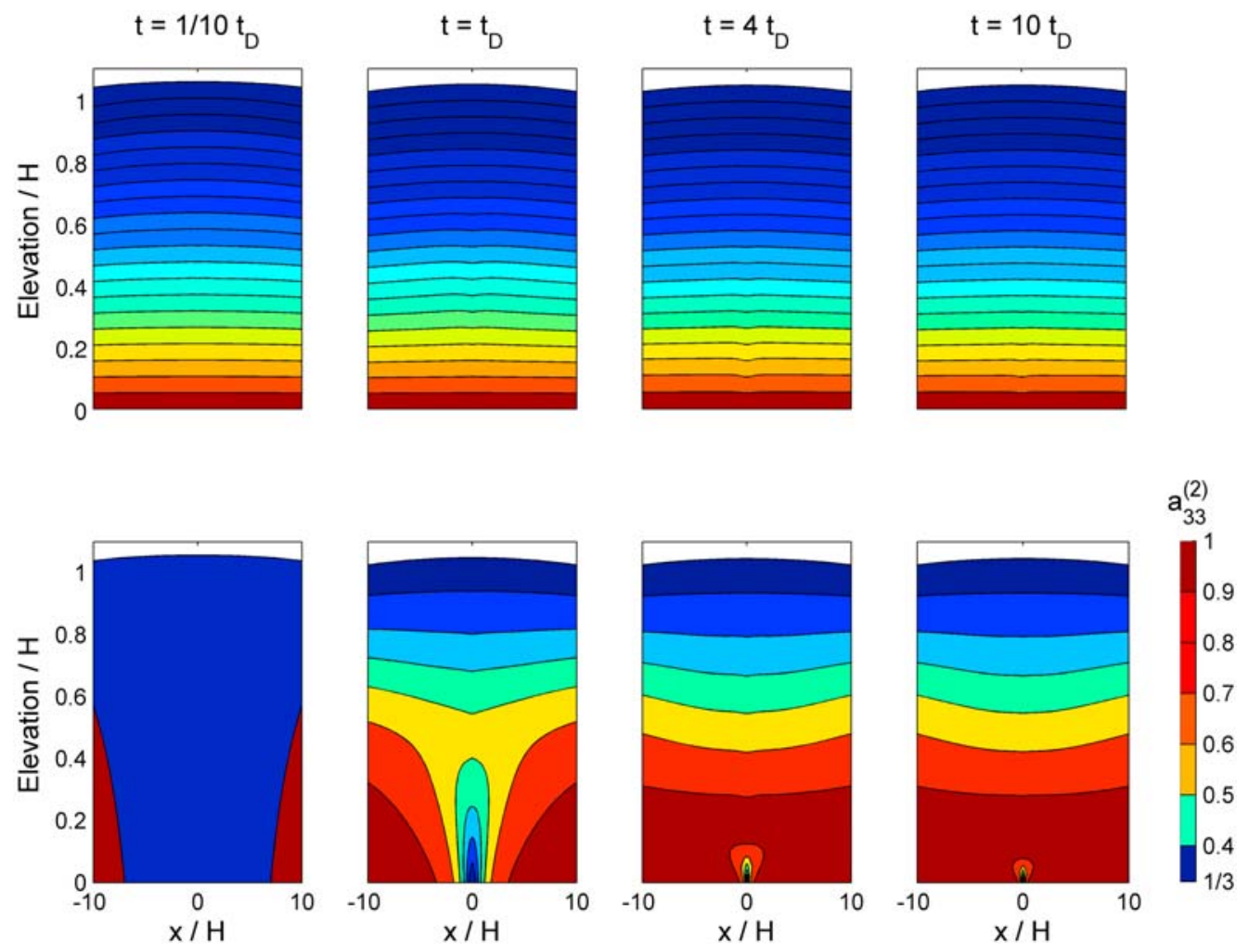

Figure 10. (top) The modeled ice stratigraphy (isochrones) and (bottom) the ice fabric (the maximum eigenvalue of the orientation tensor $a_{33}^{(2)}$ ) at different stages of the divide development assuming linear rheology $(n=1$ in equation (5)). 

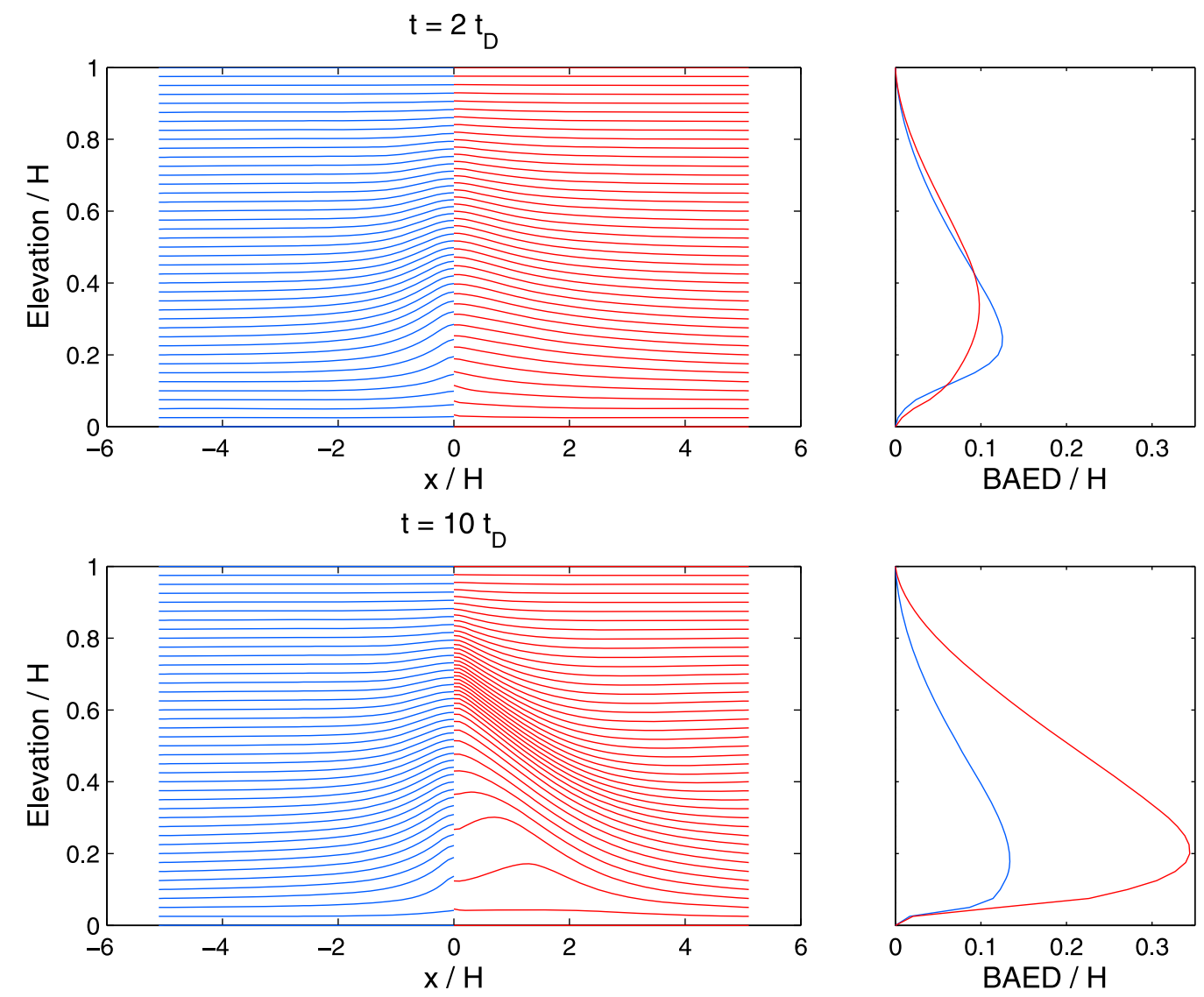

Figure 11. Comparison of the isochrones of the isotropic model (blue) and the anisotropic model (red) and the bump amplitude versus elevation distribution (BAED). (top) A divide where the fabric is not fully developed ( $2 t_{D}$ after the onset of divide flow) and (bottom) one in a nearly steady state configuration (10 $t_{D}$ after the onset of divide flow) are represented.

and 4 the same anisotropic model has been used. The fabric evolution for $n=1$ is shown in Figure 10 (bottom). Figure 10 can be compared with Figure 5 for $n=3$.

[52] For linear viscous media no Raymond bump is formed, hence anisotropy alone cannot give rise to a Raymond bump. These results agree with Pettit et al. [2007] who found that nonrandom fabric has little effect on the internal layering in a linear medium. Nonlinear viscosity appears to be an essential requirement for the formation of Raymond bumps.

[53] The steady state ice fabric for $n=1$ (Figure 10, bottom) is sharply different from the one obtained for $n=3$ (see Figure 5). Hence, in our numerical model, fabric evolution is strongly affected by the deviatoric state of stress.

\subsection{Sensitivity of Isochrone Positions to Fabric}

[54] The sensitivity of the position of isochrones to fabric was estimated by repeating the calculations described above using an isotropic rheology. In Figure 11 (left) the resulting isochrones are shown. Note, that in Figure 11 (left), the vertical coordinate of isochrones is defined as the distance away from the bed normalized with the local thickness, rather than as the distance from bed normalized with mean ice thickness. Using locally scaled vertical coordinates, i.e., scaling the distance from bed to the isochrones by the local depth, the effect of varying ice depth on isochrone positions is eliminated. As a consequence the slope of isochrones approaches zero with increasing distance away from the divide.

[55] In Figure 11 (right) the bump amplitude versus elevation distribution (BAED) is shown. The bump amplitude is defined as the difference between the (locally scaled) vertical coordinate of a given isochrone at $x=0$ and its (locally scaled) vertical coordinate far away from the divide.

[56] To allow a direct comparison of the two models, the rate factors of the anisotropic and the isotropic models, denoted as $A$ and $A_{g}$, respectively (equation (5)), were chosen so that the slope of the surfaces and the velocities at the margins of the divide area (5 times the ice thickness from the ice divide) were similar for both models.

[57] Figure 11 reveals a number of qualitative differences between calculated isochrone positions for isotropic and anisotropic ice. The nonlinear isotropic model (blue lines) produces a stack of single-peaked Raymond bumps. The nonlinear anisotropic model, on the other hand, produces both single-peaked and double-peaked Raymond bumps. The isotropic model produces no flanking synclines to the sides of the Raymond bumps while such flanking synclines are clearly visible in the steady state isochrones calculated with the anisotropic model. Although not seen in Figure 11, only the anisotropic model produces concave surface 
shoulders. In addition to these significant qualitative differences, the calculated bump amplitude versus elevation distribution (BAED) differs significantly between the two models (see Figure 11). Maximum steady state bump amplitudes are about twice as large for anisotropic ice as compared to those for isotropic ice.

\section{Discussion}

[58] The novel feature of our model calculations is the inclusion of induced fabric development in combination with nonlinear rheology. In contrast to Pettit et al. [2007], our fabric is not constrained by measurements, but allowed to change with time as determined by the fabric evolution equation (equation (6)). The strength of the fabric, as defined by the largest eigenvalue of the second-order orientation tensor $\left(a_{33}^{(2)}\right)$, varies spatially in a complicated fashion (see Figure 5). In tune with the generic modeling approach used here, we have not attempted a direct comparison with measured fabric from any particular ice divide. However, the overall resulting steady state orientation of the $c$ axis shares features commonly observed where tensile stresses dominate, i.e., isotropic ice near the surface, a vertical girdle fabric further below, and vertically aligned single-maximum fabric close to the bed. In addition, we find that the model is capable of producing a number of longobserved but poorly understood features of the flow of ice divides such as the double-peaked Raymond bumps, flanking synclines, and concave shoulders (see Figure 3 for definition of terms).

[59] Like Pettit et al. [2007] we find that unless ice is modeled as a nonlinear fluid, anisotropy does not affect flow around ice divides significantly. When ice is modeled as a nonlinear fluid we find, in further agreement with Pettit et al. [2007], that the amplitudes of the Raymond bumps are significantly larger for anisotropic ice than for isotropic ice. The increase in the size of Raymond bumps can be close to twofold. Hence, caution must be exercised in any quantitative analysis of Raymond bumps that does not include the effects of crystal fabric on the flow.

[60] Transient calculations show that Raymond bumps evolve in a number of stages (see Figures 4-7), the manifestation of double-peaked Raymond bumps and flanking synclines being the last stage of that development. A stack of single-peaked Raymond bumps can potentially be an indication of a flow regime that is not fully developed. In our model we find the timescale for the development of Raymond stacks to be on the order of the characteristic timescale $t_{D}=H / a$, where $a$ is the accumulation rate and $H$ the ice thickness. In Table 1 the characteristic timescale for a number of ice divides is listed. As can be seen from Table 1, the characteristic timescales vary widely. For example, for the Fuchs Piedmont ice divide $t_{D}$ is on the order of 400 years, while $t_{D}$ for Dome $\mathrm{C}$ is around 144000 years. The large variability in the characteristic time of ice divides may explain why Raymond bumps are sometimes not found, sometimes only single peaked, and sometimes double peaked. We find that given sufficient time, double-peaked Raymond bumps will always form underneath ice divides.

[61] The occurrence of linear features in satellite imagery parallel to the ridge of ice divides (see Figure 1) has often been reported [e.g., Lucchitta et al., 1987; Goodwin and
Vaughan, 1995] but their causes have not been understood. A simple inspection of available satellite imagery reveals the existence of such double- and triple-ridge features in imagery from a great number of Antarctic ice divides (e.g., Kealey Ice Rise, Fletcher Promontory, Korff Ice Rise, Latady Island, Spaatz Island and Lyddan Ice Rise) while many other divides with similar characteristics display no such features. Goodwin and Vaughan [1995] showed the origin for the double/triple-ridge features to be topographic concavities, i.e., concave shoulders, running parallel to the ridge to both sides. They suggested that concave shoulders might indicate ongoing migration of the divide position. Our modeling suggests, to the contrary, that concave shoulders are caused by anisotropic ice fabric that has evolved under stationary conditions for a time comparable to, or larger than, the characteristic time. Hence, rather than being indicative of change, they are signs of long-term stability.

[62] The flanking synclines in isochrones, sometimes found at the sides of the Raymond stack (see Figure 2), have previously been described by Parrenin and Hindmarsh [2007]. They show that the occurrence of flanking synclines can be explained by assuming the velocity field to be of a certain type. However, they do not answer the question as to why the velocity field should be of the type needed to produce the flanking synclines. In our model, these flanking synclines are produced without the need to make any specific assumption about the velocity field. Modeling experiments suggest that flanking synclines are manifestations of the effects of crystal fabric on flow near an ice divide.

[63] One of the most noticeable features of the internal structure of ice divides detected with ice-penetrating radars are the double-peaked Raymond bumps (see Figure 2). Single-peaked Raymond bumps are a well-known consequence of nonlinear ice rheology [Raymond, 1983]. The lowest deviatoric stresses in the divide area are found near the base of the divide. Due to the dependency of the effective ice viscosity on the deviatoric stress tensor, the ice therefore becomes significantly harder near the base as compared to the surrounding areas. This region of "hard" ice acts as an impediment to flow, altering the trajectories and forming the Raymond anticline in the ice stratigraphy. The central syncline, on the other hand, does not require nonlinear ice rheology. Figure 10 shows how a central syncline is formed for anisotropic linear viscous media. No such syncline is formed for an isotropic linear medium.

[64] In our model the fabric is induced by the flow, and the flow is in turn affected by the fabric. The effects on this coupling between flow and fabric on isochrones can be difficult to predict as anisotropy can facilitate ice deformation in one direction and at the same time hamper deformation in another direction. The development of single maximum ice fabric centered on the vertical within the lowermost $1 / 3 \mathrm{rd}$ of the ice column facilitates shear of ice $\left(\partial_{z} u\right)$ off the axis of the ice divide. This effect can clearly be seen in Figure 7 (bottom), by inspecting how the boundaries of the area defined by $\left|\hat{D}_{x z}\right|>10$ change as the fabric evolves from random to a fully developed fabric. The fabric development has profound effects on the distribution of strain rate and velocity. As Figure 7 shows, for the lower half of the ice column and over a horizontal distance of 
about 2-3 ice thicknesses away from the axis of the ice divide (i.e., approximately $|x|<3$, and $z<0.5$ ), shear rates decrease in magnitude with depth instead of increasing as would otherwise be expected. A further consequence is that within this region (absolute) vertical velocities reach a local maximum as a function of horizontal distance at $x=0$ (see Figure 6 , bottom), and a zone is formed where horizontal velocity increases with depth rather than decreasing. The maximum in (absolute) vertical velocity at $x=0$ draws the isochrones down and gives rise to the central syncline. The ice fabric also facilitates horizontal extension $\left(\hat{D}_{x x}\right.$ off the axis of the ice divide and some distance away from the bed. This can seen in Figure 7 (top), showing the distribution of horizontal strain rates. The effect is particularly pronounced within the depth range from about $1 / 5$ to $1 / 2$ of the ice thickness. As a consequence the isochrones are drawn down in this area giving rise to the flanking synclines.

[65] A flow regime where horizontal velocities increase with depth is referred to in glaciology as "extrusion flow". Extrusion flow has previously only been shown to be a theoretical possibility in the vicinity of undulating bed [Gudmundsson, 1997a, 1997b].

[66] Stratigraphy of ice divides has previously mostly been studied assuming isotropic behavior of ice [e.g., Hindmarsh, 1996; Nereson et al., 1998a, 1998b; Nereson and Raymond, 2000, 2001; Nereson and Waddington, 2002; Conway et al., 1999; Martín et al., 2006]. However, anisotropic rheology gives rise to a number of new qualitative effects on flow (see, e.g., Figure 11). Furthermore, for the induced anisotropic rheology model used here, steady state Raymond bump amplitudes are approximately twice as large as an isotropic model would suggest. In any quantitative study of an ice divide stratigraphy, the use of an isotropic model may therefore be misguided. While we caution against the use of isotropic models for flow situations where anisotropy can be expected to be of importance, our results do suggest that anisotropy primarily affects flow in the later stages of ice divide development.

[67] In accordance with previous studies [e.g., Mangeney et al., 1997; Pettit et al., 2007] we find ice fabric development to have the potential to affect significantly the age distribution of ice around ice divides. Clearly visible in Figure 11 is the effect of ice fabric on the age versus depth distribution. As Figure 11 shows, the depositional age of the ice increases initially considerably faster with depth in the anisotropic case (red) than in the isotropic case (blue). Close to the bed the situation is reversed and there it is the depositional age of the isotropic ice that increases faster with depth. This suggests that results of ice core dating from ice divides using both isotropic and anisotropic models will differ significantly. Since we find that only our anisotropic model is capable of producing a number of observed qualitative aspects of flow at ice divides that have not been explained hitherto using isotropic models, we stress that caution must be exercised in using isotropic flow models for dating ice cores.

[68] In the field examples we have shown in this study: Fuchs Piedmont, Fletcher Promontory and Kealey Ice Rise (Figure 1), the influence of temperature and recrystallization, as discussed in sections 2.1 and 2.3 , is expected to be small. Nevertheless, the question of how they may influence the ice flow and fabric development remains open. If the temperature at the base remains well below the melting point the effects are presumably rather limited [e.g., Hvidberg, 1996; Martín et al., 2006], but potentially significant if the base of the divide is at melting point and basal sliding is important [e.g., Pettit et al., 2003; Martín et al., 2009].

[69] We have not considered the effects of recrystallization on ice fabric. There are three main dynamic recrystallization regimes for polar ice: (1) normal grain growth which has no direct effect on fabric, except modifying the size of the grains; (2) rotation recrystallization which, for a vertical compression, is expected to counteract the normal grain growth and slow down the fabric development; and (3) migration recrystallization which produces grains orientated favorably to the state of stress [e.g., Gagliardini et al., 2009]. The consequences of ice softening due to migration recrystallization are unclear, but might lead to a reduction in the amplitude of the Raymond antisyncline. Including recrystallization processes would most likely give rise to a less developed fabric.

[70] Other effects that are known to affect the ice flow in the ice divide area and reduce the Raymond effect are the along-ridge flow [Martín et al., 2009] and the divide migration [e.g., Nereson et al., 1998b; Martín et al., 2009].

[71] Our model results indicate that some of the characteristic features of the radargrams from Fuchs Piedmont, Fletcher Promontory and Kealey Ice Rise shown in Figure 2, double peaked Raymond bump, flanking synclines, and concave shoulders parallel to the ice ridge (Figure 1), are consequences of a long-term development of the ice fabric relative to the characteristic timescale of the divide. Hence, divides exhibiting these features are ideal locations for extracting ice cores. Such ice divides can easily be identified by the concave shoulders visible in most satellite imagery as linear features running parallel to the main ridge.

\section{Summary}

[72] A number of observed aspects of internal layering of ice divides appear to be manifestations of the effects of ice fabric on flow. We reach this conclusion by modeling anisotropic ice flow using a full Stokes model, where fabric is described in terms of time-dependent second- and fourthorder orientation tensors. The fabric development is based on a strain-induced evolutionary equation. The anisotropic ice viscosity is, in addition, nonlinear, i.e., dependent on the state of stress.

[73] The calculated fabric distribution is realistic, with isotropic ice close to the surface, vertical girdle fabric further below, and vertically oriented single-maximum fabric toward the bed. Our confidence in the model is strengthened by the fact that the model produces a number of observed qualitative features in internal layering and surface topography that have hitherto been unexplained. These features include: concave surface undulations to both sides of the ice divide, synclines in internal layering to both sides of the well-known Raymond bumps, and doublepeaked Raymond bumps in the vicinity of the bed. None of these feature can be explained using the standard power law ice rheology currently commonly used in glaciology. 
Caution must be exercised in any quantitative modeling of ice divides that ignores the effect of fabric on flow.

\section{Appendix A: Galerkin Approximation of the Stokes System for an Orthotropic Material Under Plane Strain}

[74] Assuming plane strain conditions $\left(D_{y y}=D_{x y}=D_{y z}=0\right)$ we find that for the rheology described by equation (4), the flow law can be written in the form

$$
\left(\begin{array}{c}
S_{x x} \\
S_{y y} \\
S_{z z} \\
S_{x z}
\end{array}\right)=2\left(\begin{array}{ccc}
\eta_{x x x x} & \eta_{x x z z} & \eta_{x x x z} \\
\eta_{y y z z} & \eta_{y y x x} & \eta_{y y x z} \\
\eta_{z z x x} & \eta_{z z z z} & \eta_{z z x z} \\
\eta_{x z x x} & \eta_{x z z z} & \eta_{x z x z}
\end{array}\right)\left(\begin{array}{c}
D_{x x} \\
D_{z z} \\
D_{x z}
\end{array}\right)
$$

where $\eta_{i j k l}(i, j, k, l=\{x, y, z\})$ is the viscosity tensor in the reference frame $(x, y, z)$. In Appendix $\mathrm{C}$, we show how the viscosity tensor can be expressed in terms of rheological parameters and the two orientation tensors.

[75] The Galerkin approximation with velocity pressure mixed formulation of the Stokes system (equations (1a) and (1b)) [e.g., Quarteroni and Valli, 1994, chapter 9] leads to

$$
u \approx N_{i} U_{i}, \quad w \approx N_{i} W_{i}, \quad p \approx N_{i}^{p} P_{i},
$$

where $N_{i}$ and $N_{i}^{p}$ are the shape functions and $U_{i}, W_{i}$ and $P_{i}$ are the nodal values of velocity and pressure, respectively, and

$$
\left(\begin{array}{ccc}
\boldsymbol{K}^{u u} & \boldsymbol{K}^{u w} & \boldsymbol{K}^{u p} \\
\boldsymbol{K}^{w u} & \boldsymbol{K}^{v v} & \boldsymbol{K}^{w p} \\
\left(\boldsymbol{K}^{u p}\right)^{T} & \left(\boldsymbol{K}^{w p}\right)^{T} & \mathbf{0}
\end{array}\right)\left(\begin{array}{c}
\boldsymbol{U} \\
\boldsymbol{W} \\
\boldsymbol{P}
\end{array}\right)=\left(\begin{array}{c}
\boldsymbol{T}^{u} \\
\boldsymbol{T}^{w}+\boldsymbol{B}^{w} \\
\mathbf{0}
\end{array}\right),
$$

where

$$
\begin{aligned}
K_{i j}^{u u}= & \int_{\Omega}\left(2 \eta_{x x x x} N_{i, x} N_{j, x}+\eta_{x x x z} N_{i, x} N_{j, z}\right. \\
& \left.+2 \eta_{x z x x} N_{i, z} N_{j, x}+\eta_{x z z z} N_{i, z} N_{j, z}\right) d \Omega, \\
K_{i j}^{u w}= & \int_{\Omega}\left(\eta_{x x x z} N_{i, x} N_{j, x}+2 \eta_{x x z z} N_{i, x} N_{j, z}\right. \\
& \left.+\eta_{x z x z} N_{i, z} N_{j, x}+2 \eta_{x z z z} N_{i, z} N_{j, z}\right) d \Omega, \\
K_{i j}^{w u}= & \int_{\Omega}\left(2 \eta_{x z x} N_{i, x} N_{j, x}+\eta_{x z x z} N_{i, x} N_{j, z}\right. \\
& \left.+2 \eta_{z z x x} N_{i, z} N_{j, x}+\eta_{z z x z} N_{i, z} N_{j, z}\right) d \Omega, \\
K_{i j}^{w w}= & \int_{\Omega}\left(\eta_{x z x z} N_{i, x} N_{j, x}+2 \eta_{x z z} N_{i, x} N_{j, z}\right. \\
& \left.+\eta_{z z x z} N_{i, z} N_{j, x}+2 \eta_{z z z z} N_{i, z} N_{j, z}\right) d \Omega, \\
K_{i j}^{u p}= & -\int_{\Omega} N_{i, x} N_{j}^{p} d \Omega, \\
K_{i j}^{w p}= & -\int_{\Omega} N_{i, z} N_{j}^{p} d \Omega, \\
T_{i}^{u}= & \int_{\Gamma} N_{i}\left(\sigma_{x x} n_{x}+\sigma_{x z} n_{z}\right) d \Gamma, \\
T_{i}^{w}= & \int_{\Gamma} N_{i}\left(\sigma_{x z} n_{x}+\sigma_{z z} n_{z}\right) d \Gamma, \\
B_{i}^{w}= & -\int_{\Omega} \rho g N_{i} d \Omega .
\end{aligned}
$$

Here $\Omega$ and $\Gamma$ represent the numerical domain and its boundary. The numerical scheme uses quadrilateral elements with isoparametric mapping and $2 \times 2$ Gaussian integration. Within each element, the velocities vary bilinearly and the pressure is constant. Details are discussed by Martín [2003] and Martín et al. [2003].

\section{Appendix B: Semi-Lagrangian Discretization of the Fabric Evolution}

[76] The fabric evolution equation is solved by means of a two-dimensional semi-Lagrangian method using a twotime level scheme [Staniforth and Côté, 1991]. The semiLagrangian approximation can be written as

$$
\frac{\boldsymbol{a}_{+}^{(2)}-\boldsymbol{a}_{0}^{(2)}}{\Delta t}=\boldsymbol{W}_{\frac{1}{2}} \boldsymbol{a}_{\frac{1}{2}}^{(2)}-\boldsymbol{a}_{\frac{1}{2}}^{(2)} \boldsymbol{W}_{\frac{1}{2}}-\left(\boldsymbol{D}_{\frac{1}{2}} \boldsymbol{a}_{\frac{1}{2}}^{(2)}+\boldsymbol{a}_{\frac{1}{2}}^{(2)} \boldsymbol{D}_{\frac{1}{2}}\right)+2 \boldsymbol{a}_{\frac{1}{2}}^{(4)}: \boldsymbol{D}_{\frac{1}{2}},
$$

where the subscripts " + ", " $\frac{1}{2}$ " and " 0 " denote evaluation at arrival point $(\mathbf{x}, t+\Delta t)$, the midpoint $\left(\mathbf{x}, t+\frac{\Delta t}{2}\right)$ and the departure point $(\mathbf{x}, t)$, respectively. $\boldsymbol{\alpha}_{D}$ is the distance the fluid particle is displaced in time $\Delta t$,

$$
\begin{aligned}
\boldsymbol{\alpha}_{D} & =\Delta t \mathbf{u}^{*}\left(\mathbf{x}-\frac{\boldsymbol{\alpha}_{D}}{2}, t+\frac{\Delta t}{2}\right) \\
\mathbf{u}^{*}\left(\mathbf{x}, t+\frac{\Delta t}{2}\right) & =\frac{3}{2} \mathbf{u}(\mathbf{x}, t)-\frac{1}{2} \mathbf{u}(\mathbf{x}, t-\Delta t) .
\end{aligned}
$$

[77] This equation is solved iteratively. $\boldsymbol{a}^{(2)}, \boldsymbol{a}^{(4)}, \boldsymbol{W}$ and $\boldsymbol{D}$ are evaluated between mesh points, using a bicubic spatial interpolation.

\section{Appendix C: Inversion of the Orthotropic Rheology}

[78] The orthotropic ice flow law employed in this paper (equation (4)) expresses the strain rate tensor as a function of the stress tensor. However, the Galerkin approximation of the Stokes system, described in Appendix A (equation (A1)), requires the inversion of the rheology, i.e., the stress tensor to be expressed in terms of the strain rate tensor.

[79] For simplicity, we invert the flow law in the local orthotropic frame $\left(e_{1}, e_{2}, e_{3}\right)$; that is, the coordinate system where the second-order orientation tensor $\left(\boldsymbol{a}^{(2)}\right)$ is diagonal. Once the inversion of the rheology is performed, we transform the viscosity from the local orthotropic frame to the reference frame.

[80] It can be seen in expression (6) that if we assume plane strain in the $y$ direction $D \boldsymbol{a}_{x y}^{(2)} / D t=D \boldsymbol{a}_{y z}^{(2)} / D t=0$ the only evolving nondiagonal component of $\boldsymbol{a}^{(2)}$ is $\boldsymbol{a}_{x z}^{(2)}$. Hence, we can express the transformation between the reference frame $(x, y, z)$ and the local orthotropic frame $\left(e_{1}, e_{2}, e_{3}\right)$ as a rotation in the plane $X Z$ of angle $\delta$ and we can assume that the direction $y$ is coincident with $e_{2}$. 
[81] It follows that in the orthotropic frame, the rheology (equation (4)) can be expressed as

$$
\begin{aligned}
& \left(\begin{array}{c}
D_{11} \\
D_{22} \\
D_{33} \\
D_{12} \\
D_{13} \\
D_{23}
\end{array}\right) \\
& =\psi_{0}\left(\begin{array}{cccccc}
\psi_{1111} & \psi_{1122} & \psi_{1133} & 0 & 0 & 0 \\
\psi_{1122} & \psi_{2222} & \psi_{2233} & 0 & 0 & 0 \\
\psi_{1133} & \psi_{2233} & \psi_{3333} & 0 & 0 & 0 \\
0 & 0 & 0 & \psi_{1212} & 0 & 0 \\
0 & 0 & 0 & 0 & \psi_{1313} & 0 \\
0 & 0 & 0 & 0 & 0 & \psi_{2323}
\end{array}\right)\left(\begin{array}{l}
S_{11} \\
S_{22} \\
S_{33} \\
S_{12} \\
S_{13} \\
S_{23}
\end{array}\right),
\end{aligned}
$$

where $\psi$ is known as the fluidity tensor with components,

$$
\begin{aligned}
\psi_{0} & =\frac{1}{2 \eta_{0}} \\
\psi_{1111} & =\frac{1}{9}\left(4 \alpha_{1}+\alpha_{2}+\alpha_{3}+8 \alpha_{4}+2 \alpha_{5}+2 \alpha_{6}\right)-\psi_{t} \\
\psi_{2222} & =\frac{1}{9}\left(\alpha_{1}+4 \alpha_{2}+\alpha_{3}+2 \alpha_{4}+8 \alpha_{5}+2 \alpha_{6}\right)-\psi_{t} \\
\psi_{3333} & =\frac{1}{9}\left(\alpha_{1}+\alpha_{2}+4 \alpha_{3}+2 \alpha_{4}+2 \alpha_{5}+8 \alpha_{6}\right)-\psi_{t} \\
\psi_{1122} & =\frac{1}{9}\left(-2 \alpha_{1}-2 \alpha_{2}+\alpha_{3}-4 \alpha_{4}-4 \alpha_{5}+2 \alpha_{6}\right) \\
\psi_{1133} & =\frac{1}{9}\left(-2 \alpha_{1}+\alpha_{2}-2 \alpha_{3}-4 \alpha_{4}+2 \alpha_{5}-4 \alpha_{6}\right) \\
\psi_{2233} & =\frac{1}{9}\left(\alpha_{1}-2 \alpha_{2}-2 \alpha_{3}+2 \alpha_{4}-4 \alpha_{5}-4 \alpha_{6}\right) \\
\psi_{1122} & =\alpha_{4}+\alpha_{5} \\
\psi_{1123} & =\alpha_{4}+\alpha_{6} \\
\psi_{2233} & =\alpha_{5}+\alpha_{6} .
\end{aligned}
$$

And

$$
\begin{aligned}
& \alpha_{1}=\lambda_{1}\left(a_{11}^{(2)}-4 a_{1122}^{(4)}-4 a_{1133}^{(4)}+3 a_{2233}^{(4)}\right) \\
& \alpha_{2}=\lambda_{1}\left(a_{22}^{(2)}-4 a_{2233}^{(4)}-4 a_{1122}^{(4)}+3 a_{1133}^{(4)}\right) \\
& \alpha_{3}=\lambda_{1}\left(a_{33}^{(2)}-4 a_{1133}^{(4)}-4 a_{2233}^{(4)}+3 a_{1122}^{(4)}\right) \\
& \alpha_{4}=\frac{1}{2} \beta+\lambda_{1}\left(a_{1122}^{(4)}+a_{1133}^{(4)}-a_{2233}^{(4)}\right)+\lambda_{2} a_{11}^{(2)} \\
& \alpha_{5}=\frac{1}{2} \beta+\lambda_{1}\left(a_{2233}^{(4)}+a_{1122}^{(4)}-a_{1133}^{(4)}\right)+\lambda_{2} a_{22}^{(2)} \\
& \alpha_{6}=\frac{1}{2} \beta+\lambda_{1}\left(a_{1133}^{(4)}+a_{2233}^{(4)}-a_{1122}^{(4)}\right)+\lambda_{2} a_{33}^{(2)},
\end{aligned}
$$

where $\lambda_{1}=2\left(\frac{\gamma+2}{4 \gamma-1} \beta-1\right), \lambda_{2}=(1-\beta)$ and $\psi_{t}$ is an arbitrary constant. Some algebraic manipulation is needed to ensure that in equation (C1) the trace of both deviatoric stress and strain rate tensors is null. If $\psi_{t}$ is null the fluidity matrix has no inverse.

[82] When we assume plane strain along the $e_{2}$ direction $D_{21}=D_{22}=D_{23}=0$ and equation $(\mathrm{C} 1)$ can be inverted as

$$
\left(\begin{array}{l}
S_{11} \\
S_{22} \\
S_{33} \\
S_{13}
\end{array}\right)=2 \eta_{0}\left(\begin{array}{ccc}
\eta_{1111} & 0 & 0 \\
\eta_{2211} & -\eta_{2211} & 0 \\
0 & \eta_{3333} & 0 \\
0 & 0 & \eta_{1313}
\end{array}\right)\left(\begin{array}{c}
D_{11} \\
D_{33} \\
D_{13}
\end{array}\right)
$$

where

$$
\begin{aligned}
\eta_{1111} & =\frac{1}{3} \frac{\psi_{1111}+3 \psi_{1133}+2 \psi_{3333}}{\psi_{1111} \psi_{3333}-\psi_{1133}^{2}} \\
\eta_{3333} & =\frac{1}{3} \frac{2 \psi_{1111}+3 \psi_{1133}+\psi_{3333}}{\psi_{1111} \psi_{3333}-\psi_{1133}^{2}} \\
\eta_{2211} & =\frac{1}{6} \frac{\psi_{1111}-\psi_{3333}}{\psi_{1111} \psi_{3333}-\psi_{1133}^{2}} \\
\eta_{1313} & =\frac{1}{\psi_{1313}} .
\end{aligned}
$$

[83] The components of the viscosity tensor $\boldsymbol{\eta}$ in the reference frame, can now be calculated from the viscosity tensor in the local orthotropic frame through a simple rotation by the angle $\delta$ in the $X Z$ plane.

$$
\begin{aligned}
& \eta_{x x x x}=\cos ^{4} \delta \eta_{1111}+4 \sin ^{2} \delta \cos ^{2} \delta \eta_{1313}+\sin ^{4} \delta \eta_{3333} \\
& \eta_{z z z z}=\sin ^{4} \delta \eta_{1111}+4 \sin ^{2} \delta \cos ^{2} \delta \eta_{1313}+\cos ^{4} \delta \eta_{3333} \\
& \eta_{x z x z}=\cos ^{2} \delta \sin ^{2} \delta\left(\eta_{1111}+\eta_{3333}\right)+\frac{1}{2}(1+\cos 4 \delta) \eta_{1313} \\
& \eta_{x x z z}=\cos ^{2} \delta \sin ^{2} \delta\left(\eta_{1111}-4 \eta_{1313}+\eta_{3333}\right) \\
& \eta_{z z x x}=\cos ^{2} \delta \sin ^{2} \delta\left(\eta_{1111}-4 \eta_{1313}+\eta_{3333}\right) \\
& \eta_{x x x z}=\frac{1}{2} \sin 2 \delta\left(\cos ^{2} \delta \eta_{1111}-2 \cos 2 \delta \eta_{1313}-\sin ^{2} \delta \eta_{3333}\right) \\
& \eta_{x z x x}=\frac{1}{2} \sin 2 \delta\left(\cos ^{2} \delta \eta_{1111}-2 \cos 2 \delta \eta_{1313}-\sin ^{2} \delta \eta_{3333}\right) \\
& \eta_{z z x z}=\frac{1}{2} \sin 2 \delta\left(\sin ^{2} \delta \eta_{1111}+2 \cos 2 \delta \eta_{1313}-\cos ^{2} \delta \eta_{3333}\right) \\
& \eta_{x z z z}=\frac{1}{2} \sin 2 \delta\left(\sin ^{2} \delta \eta_{1111}+2 \cos 2 \delta \eta_{1313}-\cos ^{2} \delta \eta_{3333}\right) \\
& \eta_{y y x x}=\cos 2 \delta \eta_{2211} \\
& \eta_{y y z z}=\sin \delta \eta_{2211} \\
& \eta_{y y x z}=\frac{1}{2} \sin 2 \delta \eta_{2211} .
\end{aligned}
$$

[84] Acknowledgments. This work was supported by NERC GEF loan 785. The radargram of Fletcher Promontory shown in Figure 2 was collected by Richard C. A. Hindmarsh and processed by Edward King. We 
thank them for making their data available to this study. We would like to thank Fabien Gillet-Chaulet for numerous valuable comments and his positive contribution to this work. We also would like to thank three anonymous reviewers. Their comments resulted in a significant improvement of an earlier version of the manuscript.

\section{References}

Advani, S. G., and G. L. Tucker (1990), Closure approximations for threedimensional structure tensors, J. Rheol., 34, 367-386.

Alley, R., A. Gow, and D. Meese (1995), Mapping $c$-axis fabrics to study physical processes in ice, J. Glaciol., 41(137), 197-203.

Arthern, R. J., D. P. Winebrenner, and D. G. Vaughan (2006), Antarctic snow accumulation mapped using polarization of $4.3-\mathrm{cm}$ wavelength microwave emission, J. Geophys. Res., 111, D06107, doi:10.1029/ 2004JD005667.

Castelnau, O., P. Duval, R. A. Lebensohn, and G. R. Canova (1996), Viscoplastic modeling of texture development in polycrystalline ice with a self-consistent approach: Comparison with bound estimates, J. Geophys. Res., 101(B6), 13,851-13,868.

Castelnau, O., P. Duval, M. Montagnat, and R. Brenner (2008), Elastoviscoplastic micromechanical modeling of the transient creep of ice, J. Geophys. Res., 113, B11203, doi:10.1029/2008JB005751.

Chung, D. H., and T. H. Kwon (2002), Invariant-based optimal fitting closure approximation for the numerical prediction of flow-induced fiber orientation, J. Rheol., 46, 169-194.

Comiso, J. (2000), Variability and trends in Antarctic surface temperatures from in situ and satellite infrared measurements, J. Clim., 13(10), $1674-1696$

Conway, H., B. L. Hall, G. H. Denton, A. M. Gades, and E. D. Waddington (1999), Past and future grounding-line retreat of the West Antarctic Ice Sheet, Science, 286, 280-283.

Diprinzio, C. L., L. A. Wilen, R. B. Alley, J. J. Fitzpatrick, M. K. Spencer, and A. J. Gow (2005), Fabric and texture at Siple Dome, Antarctica, J. Glaciol., 51(173), 281-290.

Durand, G., F. Gillet-Chaulet, A. Svensson, O. Gagliardini, S. Kipfstuhl, J. Meyssonnier, F. Parrenin, P. Duval, and D. Dahl-Jensen (2007), Change in ice rheology during climate variations: Implications for ice flow modelling and dating of the EPICA Dome C core, Clim. Past, 3, $155-167$

Eisen, O., I. Hamann, S. Kipfstuhl, D. Steinhage, and F. Wilhelms (2007) Direct evidence for continuous radar reflector originating from changes in crystal-orientation fabric, Cryosphere, 1(1), 1-10.

Gagliardini, O., and J. Meyssonnier (1999), Analytical derivations for the behavior and fabric evolution of a linear orthotropic ice polycrystal, J. Geophys. Res., 104(B8), 17,797-17,810.

Gagliardini, O., F. Gillet-Chaulet, and M. Montagnat (2009), A review of anisotropic polar ice models: From crystal to ice-sheet flow models, in Physics of Ice Core Records, vol. 2, edited by T. Hondoh, Yoshioka, Kyoto, Japan, in press.

Gillet-Chaulet, F. (2007), Modélisation de l'écoulement de la glace polaire anisotrope et premières applications au forage de Dôme C, Ph.D. thesis, Univ. Joseph Fourier, Grenoble, France.

Gillet-Chaulet, F., O. Gagliardini, J. Meyssonnier, M. Montagnat, and O. Castelnau (2005), A user-friendly anisotropic flow law for ice-sheet modelling, J. Glaciol., 51(172), 3-14.

Gillet-Chaulet, F., O. Gagliardini, J. Meyssonnier, T. Zwinger, and J. Ruokolainen (2006), Flow-induced anisotropy in polar ice and related ice-sheet flow modelling, J. Non Newtonian Fluid Mech., 124, 33-43.

Gödert, G. (2003), A mesoscopic approach for modelling texture evolution of polar ice including recrystallization phenomena, Ann. Glaciol., 37, $23-28$.

Goodwin, A. H., and D. G. Vaughan (1995), A topographic origin for double-ridge features in visible imagery of ice divides in Antarctica, J. Glaciol., 41(139), 483-489.

Gow, A., D. Meese, R. Alley, J. Fitzpatrick, S. Anandakrishnan, G. Woods, and B. Elder (1997), Physical and structural properties of the Greenland Ice Sheet Project 2 ice core: A review, J. Geophys. Res., 102(C12), 26,559-26,575.

Gudmundsson, G. H. (1997a), Basal-flow characteristics of a linear medium sliding frictionless over small bedrock undulations, J. Glaciol., 43(143), $71-79$

Gudmundsson, G. H. (1997b), Basal-flow characteristics of a non-linear flow sliding frictionless over strongly undulating bedrock, J. Glaciol., 43(143), 80-89.

Haran, T., J. Bohlander, T. Scambos, T. Painter, and M. Fahnestock (2005), MODIS mosaic of Antarctica (MOA) image map, http://nsidc.org/MMS/ moa/moamap.html, Natl. Snow Ice Data Cent., Boulder, Colo. (Updated in 2006.)
Hindmarsh, R. C. A. (1996), Stochastic perturbation of divide position, Ann. Glaciol., 23, 93-104.

Hutter, K. (1983), Theoretical Glaciology, D. Reidel, Dordrecht, Netherlands.

Hvidberg, C. S. (1996), Steady-state thermomechanical modelling of ice flow near the centre of large ice sheets with the finite-element technique, Ann. Glaciol., 23, 116-123.

Lliboutry, L. A. (1987), Very Slow Flows of Solids: Basics of Modeling in Geodynamics and Glaciology, Martinus Nijhoff, Dordrecht, Netherlands.

Lliboutry, L. (1993), Anisotropic, transversely isotropic nonlinear viscosity of rock ice and rheological parameters inferred from homogenization, Int. J. Plast., 9(5), 619-632.

Lucchitta, B. K., J. A. Bowell, K. E. Edwards, E. M. Eliason, and H. M. Ferguson (1987), Multispectral Landsat images of Antarctica, U.S. Geol. Surv. Bull., 1696.

Mangeney, A., and F. Califano (1998), The shallow ice approximation for anisotropic ice: Formulation and limits, J. Geophys. Res., 103(B1), 691-706, doi:10.1029/97JB02539.

Mangeney, A., F. Califano, and K. Hutter (1997), A numerical study of anisotropic, low Reynolds number, free surface flow for ice sheet modeling, J. Geophys. Res., 102(B10), 22,749-22,764.

Martín, C. (2003), Modelización numérica de la dinámica de los glaciares templados y análisis de su respuesta a los cambios climáticos, Ph.D. thesis, Escuela Tec. Super. de Ing. de Telecomun., Univ. Politec. de Madrid, Madrid, Spain.

Martín, C., F. Navarro, J. Otero, M. L. Cuadrado, and M. I. Corcuera (2003), Three-dimensional modelling of the dynamics of Johnsons Glacier (Livingston Island, Antarctica), Ann. Glaciol., 39, 1-8.

Martín, C., R. C. A. Hindmarsh, and F. J. Navarro (2006), Dating ice flow change near the flow divide at Roosevelt Island, Antarctica, by using a thermomechanical model to predict radar stratigraphy, J. Geophys. Res., 111, F01011, doi:10.1029/2005JF000326.

Martín, C., R. C. A. Hindmarsh, and F. J. Navarro (2009), On the effects of divide migration, along-ridge flow, and basal sliding on isochrones near an ice divide, J. Geophys. Res., 114, F02006, doi:10.1029/ 2008JF001025

Meyssonnier, J., and A. Philip (1996), A model for the tangent viscous behaviour of anisotropic polar ice, Ann. Glaciol., 23, 253-261.

Nereson, N. A., and C. F. Raymond (2000), The accumulation pattern across Siple Dome, West Antarctica, inferred from radar-detected internal layers, J. Glaciol., 46(152), 75-87.

Nereson, N. A., and C. F. Raymond (2001), The elevation history of ice streams and the spatial accumulation pattern along the Siple Coast West Antarctica inferred from ground-based radar data from three inter-icestream ridges, J. Glaciol., 47(157), 303-313.

Nereson, N. A., and E. D. Waddington (2002), Isochrones and isotherms beneath migrating ice divides, J. Glaciol., 48(160), 95-108.

Nereson, N. A., R. C. A. Hindmarsh, and C. F. Raymond (1998a), Sensitivity of the divide position at Siple Dome, West Antarctica, to boundary forcing, Ann. Glaciol., 27, 207-214.

Nereson, N. A., C. F. Raymond, E. D. Waddington, and R. W. Jacobel (1998b), Migration of the Siple Dome ice divide, West Antarctica, J. Glaciol., 44(148), 643-652.

Parrenin, F., and R. C. A. Hindmarsh (2007), Influence of a non-uniform velocity field on isochrone geometry along a steady flowline of an ice sheet, J. Glaciol., 53(183), 612-622.

Paterson, W. S. B. (1994), The Physics of Glaciers, 3rd ed., Pergamon, Oxford, U. K.

Pettit, E. (2003), Unique dynamic behaviors of ice divides: Siple Dome and the rheological properties of ice, Ph.D. thesis, Univ. of Washington, Seattle.

Pettit, E. C., H. P. Jacobson, and E. D. Waddington (2003), Effect of basal sliding on isochrones and flow near an ice divide, Ann. Glaciol., 37 $370-376$.

Pettit, E. C., T. Thorsteinsson, H. P. Jacobson, and E. D. Waddington (2007), The role of crystal fabric in flow near an ice divide, J. Glaciol., 53(181), 277-288.

Quarteroni, A., and A. Valli (1994), Numerical Approximation of Partial Differential Equations, 1st ed., Springer, Berlin.

Raymond, C. F. (1983), Deformation in the vicinity of ice divides, J. Glaciol., 29(103), 357-373.

Robin, G. de Q. (1955), Ice movement and temperature distribution in glaciers and ice sheets, J. Glaciol., 2(18), 523-532.

Staniforth, A., and J. Côté (1991), Semi-Lagrangian integration schemes for atmospheric models: A review, Mon. Weather Rev., 119, 2206-2223.

Thorsteinsson, T. (2001), An analytical approach to deformation of anisotropic ice-crystal aggregates, J. Glaciol., 47(158), 507-516.

Thorsteinsson, T., J. Kipfstuhl, and H. Miller (1997), Textures and fabrics in the GRIP ice core, J. Geophys. Res., 102(C12), 26,583-26,599. 
Van der Veen, C. J. (1999), Fundamentals of Glacier Dynamics, 1st ed., A. A. Balkema, Rotterdam, Netherlands.

Vaughan, D. G., H. F. J. Corr, C. S. M. Doake, and E. D. Waddington (1999), Distortion of isochronous layers in ice revealed by groundpenetrating radar, Nature, 398(6725), 323-326.

Wang, Y., T. Thorsteinsson, J. Kipfstuhl, H. Miller, D. Dahl-Jensen, and H. Shoji (2002), A vertical girdle fabric in the NorthGRIP deep ice core, North Greenland, Ann. Glaciol., 35, 515-520.
Woodcock, N. (1977), Specification of fabric shapes using an eigenvalue method, Geol. Soc. Am. Bull., 88, 1231-1236.

O. Gagliardini, Laboratoire de Glaciologie et Géophysique de l'Environnement, UJF-Grenoble I, CNRS, BP 96, F-38402 Saint Martin d'Hères CEDEX, France. (gagliar@lgge.obs.ujf-grenoble.fr)

G. H. Gudmundsson, C. Martín, and H. D. Pritchard, Physical Sciences Division, British Antarctic Survey, Natural Environment Research Council, High Cross, Madingley Road, Cambridge CB3 0ET, UK. (ghg@bas.ac.uk; cama@bas.ac.uk; hprit@bas.ac.uk) 